Does better disease management in primary care reduce hospital costs? Evidence from English primary care

\author{
Mark Dusheiko* Hugh Gravelle* Stephen Martin** \\ Nigel Rice* Peter C. Smith ${ }^{\star \star *}$
}

${ }^{*}$ Centre for Health Economics

University of York

**Department of Economics

University of York

***Imperial College Business School

Corresponding author:

Professor Peter C. Smith

Imperial College Business School

Exhibition Road

London SW7 2AZ

Tel: +44 (0)20 75941904

Email: peter.smith@imperial.ac.uk 


\section{ACKNOWLEDGEMENTS}

This research was funded by the Department of Health and the Health Foundation. Nigel Rice acknowledges funding support from the Economic and Social Research Council (RES060-25-0045). The views expressed are not necessarily those of the funders. We thank Catherine Fullwood of the National Primary Care Research and Development Centre at the University of Manchester for providing us with the QOF population achievement data. We are also grateful for comments from three referees and from participants at a seminar held by the Swiss School of Public Health in Crans-Montana. 


\title{
Does better disease management in primary care reduce hospital costs? Evidence from English primary care
}

\begin{abstract}
We apply cross-sectional and panel data methods to a database of 5 million patients in 8,000 English general practices to examine whether better primary care management of 10 chronic diseases is associated with reduced hospital costs. We find that only primary care performance in stroke care is associated with lower hospital costs. Our results suggest that the $10 \%$ improvement in the general practice quality of stroke care between 2004/5 and 2007/8 reduced 2007/8 hospital expenditure by about $£ 130$ million in England. The cost savings are due mainly to reductions in emergency admissions and outpatient visits, rather than to lower costs for patients treated in hospital or to reductions in elective admissions.
\end{abstract}

Keywords: Quality. Disease management. Primary care. Hospital costs. Ambulatory care sensitive conditions. Preventative care.

JEL categories: I12, I18 


\section{Does better disease management in primary care reduce hospital costs? Evidence from English primary care}

\section{Introduction}

There is a widespread belief and hope amongst policymakers that timely disease management, in the form of encouraging behavioural change, self care by patients, and preventive medicine, can reduce demands for healthcare expenditure and improve health outcomes (HSCIC, 2005). The intention of disease management is to ensure that 'at risk' groups, or those with established chronic conditions, receive clinical best practice in the monitoring of their condition, and that recognized intermediate outcomes are achieved to reduce the risk of acute health deterioration. The hope is that better management of existing conditions and the reduction in the risk of serious complications will improve patients' health prospects, and reduce expected future health services expenditure (Congressional Budget Office, 2004).

The research evidence is however equivocal (Congressional Budget Office, 2004). Most preventive interventions are cost-increasing, and many are not even cost-effective when compared to more conventional clinical interventions. Less than $20 \%$ of studies have identified cost-saving preventive interventions (Russell, 2009). A recent review of the economic impact of disease management programs for diabetes, depression, heart failure and chronic obstructive pulmonary disease (COPD) found that only half of studies reported cost savings, mainly through reduced hospital admissions and specialist visits (de Bruin, 2011). The cost-effectiveness of disease management is therefore a critical issue. As summarized by Cohen et al (2008), "careful analysis of the costs and benefits of specific interventions, rather than broad generalizations, is critical.” In other words, it is likely that the precise population groups targeted, and the frequency and mode of implementation will be crucial determinants of an intervention's impact on health and health service costs.

In an attempt to improve the quality of disease management in primary care, pay for performance schemes have been introduced in several countries: Australia (Scott et al, 2009), 
Italy (Bruni et al, 2009), Taiwan (Lee et al, 2010), the United States (Lester et al, 2010) and the United Kingdom (Roland, 2004; Doran et al, 2006). Since 2004, UK general practitioners (GPs) have been subject to a major 'pay for performance' incentive scheme, known as the Quality and Outcomes Framework (QOF). The introduction of QOF was part of the new contract for the delivery of primary care. The contract came with considerable additional funding for general practices, and expenditure on primary care in England increased from $£ 5.8$ billion in $2003 / 04$ to $£ 7.8$ billion in $2005 / 06$. Under the QOF, about $20 \%$ of GP income was determined by practice achievement against quality indicators (National Audit Office, 2008). The QOF is probably the most radical attempt to date to embed preventive medicine and disease management into primary care and has a large number of indicators of disease management quality. Given the substantial additional funding provided to support the QOF, policymakers will want to determine whether those practices that record a better performance against QOF indicators reduce the costs patients incur in other parts of the health system.

A number of studies have used the detailed measures of disease management produced by the QOF to examine the association between practice quality scores and hospital admissions (Downing et al, 2007; Shohet et al, 2007; Bottle et al, 2008a; Bottle et al, 2008b; Kiran et al., 2010; Purdy, 2011; Bankart et al, 2010 Calderón-Larrañaga A et al , 2011 ). They have found only a weak negative, and usually statistically insignificant, association. This might be due to the ineffective nature of the incentivized interventions. However, it could also be due to the use of aggregate geographic level data, or a relatively small samples of practices, to the use of a single year of data, to other data limitations, or to the characteristics of the pay-forperformance scheme (for example, the QOF quality indicators have upper achievement thresholds of between $50 \%$ and $90 \%$ so that practices can score the maximum number of points without achieving the target for all patients).

Dusheiko et al (2010) avoid many of these problems in their analysis of practice emergency hospital admission rates for short term complications of diabetes using data on all English practices from $2004 / 5$ to $2006 / 7$. They find that moving $10 \%$ of registered diabetic patients from poor to good glycaemic control in an average practice was associated with a $14 \%$ decrease in the rate of emergency admissions for short term diabetic complications, and a $£ 1,928$ reduction in hospital costs per practice in 2006/7. However, their study was at practice level and was not able to allow for the characteristics of individual patients in practices. 
Some studies have directly investigated the impact of pay-for-performance (P4P) incentives for quality in primary care on hospital admissions and costs. Mullen et al. (2010) found that although P4P for a range of clinical quality measures in California had a positive impact on some of the clinical measures rewarded by the programs, there was no significant effect on avoidable hospital admissions. Lee et al. (2010) reported that diabetes related examinations and physician visits increased for patients enrolled in a P4P disease management program in Taiwan compared with diabetic patients not enrolled in any P4P program, while inpatient admissions and diabetes related hospitalizations and expenditure fell significantly by $12 \%$ and 35\%. Chen et al. (2010) investigated the impact of P4P for quality of care for diabetic patients in Hawaii. Patients who saw P4P-participating physicians were significantly more likely to receive better quality care compared with patients who saw non-P4P-participating physicians and improvements in care were associated with significant reductions in hospitalization. Fiorentini et al (2010) found the incentives for quality in primary care reduced related avoidable hospitalizations in the Emilia-Romagna region.

We take advantage of a major new database of hospital records for over 50 million English citizens linked to disease management quality indicators for their general practice to examine the association between quality of disease management in general practice and hospital costs. We are able improve on previous studies by using QOF data for a longer time period (2004/5 to 2007/8), and by having detailed information on the diagnostic history of individuals. The database also enabled us to examine the impact of disease management on the total hospital costs for individuals as well as their costs relating to unplanned admissions, specialist visits and planned hospital treatments. ${ }^{1}$

Section 2 discusses how general practice disease management may affect hospital costs and describes the estimation methods used to detect these effects. Section 3 describes the dataset and section 4 the estimation methods. Section 5 has the results and section 6 presents some concluding remarks.

\footnotetext{
${ }^{1}$ We do not attempt to estimate the effects of the QOF scheme on quality or on hospital costs since we have no information of pre QOF quality.
} 


\section{General practice disease management and hospital cost}

Disease management of chronic conditions in general practice is intended to improve the health of individual patients with chronic conditions via monitoring (for example, cholesterol levels for patients with coronary heart disease), preventive medicine (for example antiplatelet therapy for stroke patients, influenza immunization for vulnerable groups), and lifestyle advice for smokers or the obese. A general practice's disease management could affect hospital costs for its patients in a variety of ways. Patients incur hospital costs via emergency admissions, elective admissions and outpatient visits. Better disease management by a general practice could alter the probabilities of these three types of use and/or the costs incurred if a patient uses hospital services.

Ambulatory care sensitive conditions (ACSCs) are medical conditions for which adverse outcomes such as emergency hospital admission may be reduced by better management in primary care (AHRQ, 2004). Purdy et al (2009) estimate that a set of 19 ACSCs commonly used to monitor aspects of National Health Service (NHS) performance accounted for 14.1\% of NHS emergency admissions in England in 2005/6 and a larger set of 36 ACSCs accounted for $40.1 \%$. Thus we would expect that practices with better disease management of ACSCs would have fewer patients being admitted as emergencies for complications of ACSCs. However, it is possible that over-zealous management of some ACSCs in general practice could increase certain types of emergency admissions. For example, disease management of diabetic patients is aimed at reducing blood sugar levels and should therefore reduce emergency admissions for acute hyperglycaemic complications. But excessively aggressive management of blood sugar can increase the risk of admissions for hypoglycaemic coma (Briscoe and Davis, 2006). The targeting of patients with specified chronic conditions may also divert GP efforts away from other types of patients and increase their risk of hospitalization. On balance it is likely that better general practice disease management is associated with lower emergency admission probabilities, though there is no evidence on the overall magnitude of the association.

It is also possible that better general practice disease management will reduce costs for patients who are hospitalized as emergencies if such patients are healthier, though still ill, when admitted. Moreover, some of the investments that practices make to improve disease management, such as better record systems, employing specialist nurses, and better liaison 
with community health staff, will also enable their patients to be discharged earlier because aftercare arrangements are better.

The effect of better practice disease management on the costs of elective hospitalizations is less clear. Some elective hospitalizations are for the treatment of patients whose chronic conditions are more severe. For example, patients with heart disease requiring CABGs or PTCAs are usually admitted as elective patients, as are diabetic patients with ophthalmic complications. If better disease management reduces the probability of the disease progressing to the stage where such procedures are required then elective admissions will be reduced. On the other hand better disease management can increase the probability that patients with chronic conditions are admitted for unrelated elective procedures such as cataracts or hip replacements, either because they survive long enough to require such procedures or because patients with better controlled chronic conditions will have greater health gains from such procedures and may therefore be more likely to receive them. Improved monitoring of patients with chronic conditions may result in earlier detection of other conditions requiring treatment. Again, as with emergency admissions, if general practice disease management means that admitted elective patients are healthier, the costs of admitted patients may be lower because they are likely to develop fewer complications and to have shorter lengths of stay.

The use of outpatient departments by a practice's patients may also be affected by its disease management. Of the 60 million annual outpatient visits in England, around 20 million are for new patients referred by their GP. More active case finding may lead to GPs referring more patients to hospital outpatient departments for further testing and diagnosis. GPs may also refer more patients for elective procedures and the first step in this process is a referral to an outpatient department for a specialist to agree that the patient should receive the treatment. On the other hand elective or emergency admissions will often lead to follow up outpatient visits, and if better disease management leads to fewer inpatient stays then follow up outpatient visits will also decline.

Thus, in addition to examining the effect of disease management on a patient's total hospital costs, it will of interest to examine its effects on the differing types of hospital cost (arising from emergency admissions, elective admissions, and outpatient visits) and to decompose these effects into those due to variations in the probability of use and those due to variations 
in the intensity of use (costs of those who use the hospital). Moreover, it may also be necessary to allow for the fact that different effects of primary care disease management may occur with differing time lags. For example better control of diabetic patients' blood sugar will have a rapid effect on emergency admissions for hyperglycaemic complications. But better monitoring of their peripheral pulses will take some years to reduce the likelihood of admissions for long term neuropathological complications leading to lower limb amputations. Section 4 describes how we model these various effects in the light of the available data.

\section{Data}

We link two individual level and one practice level administrative databases to small area socio-economic and demographic data. In the English National Health Service patients who wish to obtain publicly funded NHS primary care services from general practitioners (GPs) must register with a single general practice. We had information on all patients (over 50 million) who were registered with an English practice at any time between 1 April 2001 and 1 April 2008. We also had information on all hospital inpatient episodes and outpatient visits for all patients admitted to English NHS hospitals for the same period. ${ }^{2}$ We linked the practice registration data to hospital data at individual patient level using pseudonymized NHS numbers. We then attached measures of the quality of disease management in their practices to the patients. Finally, we attached a large set of socio-economic and supply side variables to the individuals based on either their small area of residence or their general practice.

For analysis we took a 10\% random sample of patients in each English practice that had at least 1000 patients, yielding about 5 million observations per year. ${ }^{3}$

\subsection{Hospital expenditure}

For our models of patient cost the dependent variable is individual patient annual NHS hospital expenditure. ${ }^{4}$ We include expenditure on both outpatient attendances and all inpatient

\footnotetext{
${ }^{2}$ Some patients of English practices are treated in hospitals located in Wales and Scotland. Previous work has shown that dropping the small number of patients in practices near to the borders with Wales and Scotland makes no difference to estimation results (Dixon et al, 2009).

${ }^{3}$ Sutton et al (2007) report that a sample size of about 5 million individuals is sufficient to generate stable parameter estimates.
} 
hospital spells finishing in that year whether they started in the year or the previous year. We used the same set of unit costs obtained from the English Department of Health to cost spells in each of the years 2004/5 to 2007/8. We exclude costs for maternity from the calculation of total hospital costs since maternity costs are unlikely to be affected by chronic disease management. We also exclude mental health costs because of doubts about the quality of the hospital expenditure data for mental health. For 2007/8 31\% of our sample record a non-zero hospital cost with the average cost of these patients being $£ 1,383$. The average cost across all patients in our sample for $2007 / 8$ is $£ 427$. See Table 1 where we also present summary statistics for average costs and probabilities of use for emergency admissions, elective admissions and outpatient visits.

<Table 1 about here $>$

\subsection{Practice disease management quality}

We measure practice disease management quality using data from the Quality and Outcomes Framework (QOF), a P4P scheme covering all practices in the UK that was introduced in April 2004 (National Audit Office, 2008). Because of the difficulty of attributing health outcomes to specific activities in a general practice, the QOF ties incentive payments mainly to process activities over which GPs have direct control and for which there is evidence of subsequent benefits to the patient (Doran, 2008; Roland, 2004). The QOF was expected to lead to a reduction in avoidable hospital admissions by stimulating an improvement in chronic disease management (HSCIC, 2005, p2). We use the very rich practice level data extracted automatically from general practice electronic records to construct practice level measures of the quality of disease management in 10 disease areas.

There were some revisions to the QOF in 2006/7 but its basic structure remained intact over the study period. ${ }^{5}$ In the revised version there were 136 performance indicators grouped in four domains: clinical (80 indicators), organizational (43 indicators), patient experience (5 indicators), and additional services (8 indicators). Practices scored points for their

\footnotetext{
${ }^{4}$ Financial years run from 1 April to 31 March. Hospital data are available at http://www.hesonline.nhs.uk/. We exclude the costs of patients treated privately in NHS hospitals and include the costs of patients in private hospitals who were paid for by the NHS.

${ }^{5}$ The 2004/5 QOF had 1050 points for 146 indicators, with 76 clinical indicators in 11 disease areas accounting for 550 points (Department of Health, 2004).
} 
achievement against each indicator, with the maximum number of points available varying across indicators. In total a general practice could earn up to 1,000 points, each point worth $£ 125$ for an average practice. 675 of the points were for the 80 clinical indicators that covered 19 groups of conditions. QOF clinical quality determined about 10\% of GP income.

We use the clinical domain indicators to measure practice disease management quality. We ignore the organizational indicators because they are unlikely to have a direct effect on hospital expenditure and would most likely influence expenditure only through their impact on the clinical domain indicators. The clinical indicators generally measured regularity of monitoring (for example, whether a diabetic patient's blood pressure or cholesterol had been recorded in the last 15 months) and intermediate outcomes, such as whether blood pressure had been successfully controlled. Practices were awarded points according to the proportion of eligible patients for whom each target was met, with points increasing linearly between a lower threshold of $40 \%{ }^{6}$ up to an upper threshold that varied across indicators. See Table 2 for examples of indicators for practice care of stroke patients.

$<$ Table 2 about here $>$

Setting upper thresholds below $100 \%$ of maximum attainment was intended to reduce the risk that GPs would inappropriately treat some patients (Roland, 2004; Doran et al 2008). However, the upper threshold might also discourage practices from including the most hardto-reach patients because no further points are received when a practice has achieved the upper threshold (National Audit Office, 2008, p36).

Most of the clinical indicators are expressed as percentages of the eligible population, an approach designed to encourage practices to increase the number of treated patients from the appropriate set of patients. However, the eligible population for an indicator is not the number of patients with the disease (prevalence - which we denote $P$ ). Practices are able to exclude some patients from the denominator by designating them as 'exceptions' according to specified criteria. Exception reporting is intended to avoid penalising practices where, for example, patients do not attend for review, or where a medication cannot be prescribed due to a contraindication or side-effect. Thus the reported achievement used to calculate financial

\footnotetext{
${ }^{6}$ Except for the DEMENTIA 2 indicator where the lower threshold was 25\%.
} 
rewards for a clinical indicator is $N /(P-E)$ where $N$ is the number for whom the indicator is achieved and $E$ is the number exception reported for that indicator.

Practices could increase their reported achievement, and hence their financial rewards, by overstating exceptions. There is some evidence that practices did so (Doran et al, 2008; Gravelle, Sutton and Ma; 2010). Thus the reported achievement rate is not an appropriate quality indicator. Using the actual points earned by the practice would also be questionable because the upper thresholds for earning points means that, for example, two practices with reported achievements of $60 \%$ and $90 \%$ on the Stroke 8 indicator would get the same number of points (see Table 2).

In this paper we therefore measure quality by the population achievement rates calculated as $N / P$ (i.e. not adjusted for exceptions), though, as we note in the results section, measuring quality by reported achievement $(N /(P-E))$ makes no substantive difference. For each disease domain we calculate the domain population achievement as a weighted average of the population achievement rates on the indicators in that domain. The weight attached to an indicator is the share of the maximum points that it attracts in the relevant clinical domain. ${ }^{7}$

Some indicators refer to a subset of patients in a disease area and there is no information on the number of patients in these subsets to enable us to calculate our quality measure. We therefore base our quality measures only on indicators that refer to all patients with a disease (Doran et al, 2006) For 2007/8 ee use 48 clinical quality indicators to calculate overall quality measures for the 10 disease areas shown in Table 3 that cover most of the major chronic conditions encountered in general practice.

$<$ Table 3 about here $>$

Table 4 has summary statistics for 2007/8 for our quality measures for the ten clinical disease areas and Table 5 reports their correlation coefficients. Although the rates are positively correlated, many of the correlations are modest, suggesting considerable variations in levels of attainment within a practice across different domains. The mental health achievement rate

\footnotetext{
${ }^{7}$ For details of the construction of the population achievement rates see Doran et al (2006).
} 
is the least well correlated with the other sub-domains. Correlations for other years are similar.

$<$ Tables 4 and 5 about here $>$

\subsection{Covariates}

We use three sets of covariates: individual needs variables, small area needs variables and indicators of supply. ${ }^{8}$ The individual needs variables are:

(a) age (5 year bands) at the beginning of the financial year and gender (38 age/gender band dummies).

(b) previous morbidity for each individual as measured by 152 dummy variables based on ICD10 inpatient diagnosis categories used by the NHS Information Centre. ${ }^{9}$ The dummy for a morbidity category was set equal to 1 if the individual had one or more hospital spells in either of the previous two years with any diagnosis in the relevant subset of ICD10 categories. $^{10}$

(c) four hospital encounter variables (the number of inpatient episodes in the previous two years, the number of outpatient attendances in the previous two years, and two dummy variables indicating whether the individual had a priority outpatient referral or received any treatment in the course of an outpatient attendance in the previous two years). The rationale is that the number of times an individual has been admitted to hospital or attended an outpatient clinic in the past conveys something about the intensity of their morbidity experience, over and above the information contained in the binary ICD10 morbidity variables, which do not reflect repeated spells in the same ICD10 category.

(d) two indicators for whether the individual patient had a private inpatient spell or a private outpatient attendance in an NHS hospital in the previous two years. Our expenditure measure is for costs borne by the NHS. Some patients treated in NHS hospitals choose to pay to be treated as private patients to reduce their waiting times or to be able to choose their surgeon. Individuals who have been private patients in the past are more likely to use private provision in the future, and will therefore other things equal incur less NHS expenditure.

\footnotetext{
${ }^{8}$ These variables are more fully described in PBRA Team (2010).

${ }^{9}$ See http://www.hesonline.nhs.uk/Ease/servlet/ContentServer?siteID=1937\&categoryID=202.

${ }^{10}$ The morbidity indicators do not indicate severity of the condition, merely its presence or absence. It would be useful in future work to include more refined measures of mobidity for particular conditions from data sets based on practice clinical records.
} 
For the attributed (small area) needs variables we had over 160 small area level measures of population socio-economic characteristics that might plausibly be linked to variations in hospital utilization. These included data from the 2001 Census and the Indices of Multiple Deprivation 2007 that were attributed to each individual via their Lower Super Output Area of residence. ${ }^{11}$ We also had information on disease prevalence rates for each practice derived from the rates reported by practices as part of the QOF.

The attributed supply variables included over 90 measures of local health system characteristics that might affect hospital utilization. They included practice characteristics such as the number of patients per GP and measures of the accessibility of different types of health care facilities from the small area in which the patient lives. The supply variables also included measures of accessibility such as distance to providers and waiting times at local hospitals.

We also included 151 dummy variables for the Primary Care Trust (PCT) responsible for the general practice with which the individual is registered. PCTs were the administrative entity with prime responsibility for purchasing NHS services from local hospitals on behalf of their local populations, typically about 350,000 individuals. The dummies are intended to capture factors such as variations in aggregate PCT spending levels and PCT commissioning policies that may affect hospital costs. Because patients in many PCTs tend to use one main hospital provider the PCT dummies will also pick up variations in hospital diagnosis recording practices, and hospital treatment thresholds. ${ }^{12}$

\section{Estimation}

Given the large samples of data together with the extensive set of covariates to be considered, we adopt a pragmatic approach, starting with cross-sectional models for exploratory analyses and building up to dynamic panel data models. The cross-sectional models allow us to explore specification of models that capture the impact of practice quality on hospital costs while controlling for confounding factors. They also allow us to investigate the impact of

\footnotetext{
${ }^{11}$ See http://www.neighbourhood.statistics.gov.uk/dissemination/. There are 32,482 lower super output areas (LSOAs) with a minimum population of 997 and a mean population of 1,513.

${ }^{12}$ We also estimated models using the proportion of a practice's expenditure incurred at each hospital in England to control for hospital effects with very similar results.
} 
different practice quality measures and the lag between quality and hospital costs. The impact of quality is then explored separately for total costs (zero and positive expenditures) arising from emergency admission, elective admissions and outpatient visits. We then consider the impact of disease management on the probability of incurring hospital expenditure and separately on the level of costs conditional on having incurred expenditures (positive expenditures only). Finally, we estimate dynamic panel data models of total hospital costs controlling for persistence in individual expenditures and heterogeneity in practice effects brought about, for example, by differences in referral decisions.

The distribution of total hospital costs for individuals generally has a spike at zero and a long right-hand tail. They also tend to be heteroskedastic. In small to moderate samples these characteristics can be challenging to ordinary least squares (OLS) regression and alternatives including generalized linear models and ordinary least squares on a transformed dependent variable are often used (e.g. Buntin and Zaslavsky, 2004; Manning et a;, 2005). For the dataset used in this study the performance of alternative estimators was investigated in depth and it was found that, because of the very large sample sizes available, OLS models of untransformed expenditure outperformed alternatives in terms of predictive power (Dixon et al, 2009). This is in line with findings from other researchers using large samples (Dunn et al, 2003, Ellis and McGuire, 2007). Accordingly, when modelling the level of costs we estimate linear specifications using OLS (and panel data counterparts) in what follows.

\subsection{Cross section models}

We first estimate cross section models of total hospital costs

$$
c_{i j p}=\beta_{0}+q_{j p}^{\prime} \beta_{q}+x_{i j p}^{\prime} \beta_{x}+m_{i j p}^{\prime} \beta_{m}+n_{i j p}^{\prime} \beta_{n}+v_{i j p}^{\prime} \beta_{v}+s_{i j p}^{\prime} \beta_{s}+P C T_{p}^{\prime} \beta_{P C T}+\varepsilon_{i j p}
$$

where $c_{i j p}$ is expenditure in the financial year 2007/08 on patient $i$ in practice $j$ in PCT $p$ on 1 April 2007. $q$ is a vector of measures of general practice disease management quality, $x$ is a vector of 37 age and gender dummies. $m$ is a vector of 152 morbidity indicators based on ICD10 diagnoses for inpatient episodes and $v$ vector of 4 encounter variables, with both vectors based on data from the previous two years. $n$ is vector of small area needs variables attributed to individuals on the basis of their place of residence and $s$ a vector of supply variables based on practice characteristics and accessibility of health care facilities (all as of 1 
April 2007). PCT is a vector of 151 PCT dummy variables and $\varepsilon$ is an error term. The model is estimated via OLS using practice cluster robust standard errors.

We retained vectors of individual characteristics $x, m$ and $v$ in all specifications. However, the initial model had over 500 potential explanatory variables including 250 attributed needs and supply characteristics $(n, v, s)$. To search for a parsimonious specification of the attributed variables these latter variables we start from a full model (containing all variables) and eliminate attributed variables on the basis of their $t$ statistics. We first drop attributed variables with $|t|<0.2$ and re-estimate and drop attributed variables with $|t|<0.4$. We repeat increasing the required absolute $t$ statistic until all remaining attributed variables have $|t| \geq$ 2.00. We then drop attributed variables with counter-intuitive signs, and re-estimate the models. We repeat these steps until only those attributed variables with a significance level of $1 \%$ or better. The resulting model is then used as the basis for investigating the impact of quality measures on hospital costs.

We next estimate probit cross-section models of the probability of incurring hospital expenditure in 2007/8 $\operatorname{Pr}\left(y_{i j p}\right)$, where $y_{i j p}=1$ if $c_{i j p}>0$ and $y_{i j p}=0$ otherwise, with practice cluster robust standard errors. We also estimate OLS cross section models for individuals with positive expenditure $c_{i j p}>0$, again with practice cluster robust standard errors. We use the set of regressors selected in the final parsimonious version of (1).

\subsection{Panel data models}

We extend the cross-sectional analysis to exploit the longitudinal dimension of the data and estimate panel data models for 2004/5 to 2007/8

$$
\begin{aligned}
c_{i j p t}=\beta_{0}+q_{j p t}^{\prime} \beta_{q}+x_{i j p t}^{\prime} \beta_{x}+m_{i j p t}^{\prime} \beta_{m}+n_{i j p t}^{\prime} \beta_{n}+ & v_{i j p t}^{\prime} \beta_{v}+s_{i j p t}^{\prime} \beta_{s} \\
& +P C T_{p}^{\prime} \beta_{P C T}+\varphi_{t}+\mu_{j p}+\varepsilon_{2 i j p t}
\end{aligned}
$$

$\varphi_{t}$ is a year effect, $\mu_{j p}$ is a practice-specific time invariant error term and $\varepsilon_{2 i j p t}$ is a time and individual pooled error term. Note that the pooled error term could be decomposed into an unobserved individual specific effect and an idiosyncratic error term: $\varepsilon_{2 i j p t}=\alpha_{i j p}+\zeta_{i j p t}$. However, due to computational constraints of estimating three-way error-component panel data models with such a large set of variables and observations we pool these two 
components of the error. This is unlikely to be overly restrictive given that variability in the quality measures occurs across time and practices and not across individuals within practices.

First we estimate (2) assuming, separately, that the $\mu_{j p}$ are fixed and random practice effects. We then use a dynamic specification by including an autoregressive one-period lag of the expenditure variable to reflect persistence, or state dependence, in the use of health care not fully reflected through the set of morbidity and encounter variables:

$$
\begin{aligned}
c_{i j p t}=\beta_{0}+q_{j p t}^{\prime} \beta_{q}+x_{i j p t}^{\prime} \beta_{x}+m_{i j p t}^{\prime} \beta_{m}+n_{i j p t}^{\prime} \beta_{n}+ & v_{i j p t}^{\prime} \beta_{v}+s_{i j p t}^{\prime} \beta_{s}+\gamma c_{i j p t-1} \\
& +P C T_{p}^{\prime} \beta_{P C T}+\varphi_{t}+\mu_{j p}+\varepsilon_{2 i j p t}
\end{aligned}
$$

Persistence in health expenditures is captured through the parameter . For example, should an individual experience a shock to health (via $\varepsilon_{2 i j p t}$ ) resulting in higher hospital expenditure in period $t$, then $\hat{\gamma}>0$ will imply that health care expenditures will be higher in future periods.

To derive consistent estimates of the parameters of (3) we need to allow for the correlation between the lagged dependent variable $c_{i j p t-1}$ and the error $\varepsilon_{2 i j p t}$ and in particular via an unobserved individual effect ie $\varepsilon_{2 i j p t}=\alpha_{i j p}+\zeta_{i j p t}$. In the context of models with discrete outcomes this is often referred to as the problem of initial conditions (Heckman, 1981). Wooldridge (2002) proposes an approach to deal with the initial conditions problem intended for non-linear dynamic random effects panel data models. It involves modelling the distribution of the unobserved effect conditional on the initial value of the dependent variable (first wave observation) and any exogenous explanatory variables (see Contoyannis et al. (2004) for an application). Following the spirit of this approach but adapting to our linear model we parameterise the unobserved individual effect as follows:

$$
\alpha_{2 i j p}=\kappa_{0}+\kappa_{1} C_{i j p 1}+\bar{Z}_{i j p}^{\prime} \kappa_{2}+\varepsilon_{i j p}
$$

where $\bar{z}_{i j p}$ is a vector of the average values over time within individuals of the exogenous variables $(x, m, n, s) . \quad \varepsilon_{i j p}$ is an error term assumed to be independent of $\bar{z}_{i j p}^{\prime}, q$, the initial condition $c_{i j p 1}$ and the residual pooled error term $\left(\varepsilon_{2 i j p t}-\alpha_{2 i j p}\right)$. Substituting (4) into (3) gives a model with regressors at time $t$ augmented to include $c_{i j p 1}$ (costs in year 2004/5) and $\bar{Z}_{i j p}$. This model can then be estimated using random practice effects. Note that we would expect 
the coefficient $\hat{\kappa}_{1}$ to be positive as it is informative about the relationship between the individual unobserved effect and initial hospital expenditures.

Blundell, et al. (2002) suggest modelling individual heterogeneity in dynamic count data models as a function of baseline or pre-sample averages of the dependent variable and show this to perform well in simulations. To further control for practice level heterogeneity we adapt this approach by averaging individual baseline costs $C_{i j p 1}$ across individuals within practices to construct a variable representing practice baseline costs based on data from the initial period 2004/5. In a similar way to the augmented regression in (4), this constructed variable $\bar{c}_{j p 1}$ can used as a regressor in the parameterization of the unobserved practice effect as $\mu_{j p}=\tau_{0}+\tau_{1} \bar{c}_{j p 1}+\varepsilon_{j p}$.

\section{Results}

\subsection{Cross-section models for 2007/8 total cost}

Although our final parsimonious model contained only five of the 250 attributed needs and supply variables, there was only a small loss in explanatory power compared with the initial model with a full set of covariates (the $\bar{R}^{2}$ fell from 0.2662 to 0.2654 ). The signs and coefficients on the covariates from the parsimonious model are generally plausible. ${ }^{13}$ The variables that make the largest contribution to explanatory power are the 152 past morbidity indicators and the age/gender categories. Unsurprisingly, individuals with past morbidity generally have higher costs. Costs for both males and females decrease with age until 25 years and then increase (see Appendix Table A1). There is no hump at child bearing age for women because maternity costs are excluded from the total cost dependent variable.

The coefficients on the four hospital encounter variables are significant and positive. They imply that, for example, the number of times an individual has been admitted to hospital or attended outpatients in the past conveys something about the intensity of their morbidity experience, over and above the information contained in the binary ICD10 morbidity

\footnotetext{
${ }^{13}$ Appendix Table A1 reports coefficients on age/gender, past hospital use, and attributed needs and supply variables for the main cross-section and panel data models. The complete set of coefficients (including the individual past morbidity dummies and PCT dummies) are in the working paper Dushieko et al (2011).
} 
variables. The two private health care variables have a negative effect on NHS costs. This is as expected since individuals who have been private patients in the past are more likely to use private facilities in the future when they are ill and thus will generate lower NHS expenditure. The five attributed small areas needs variables that are significant in the final parsimonious model have plausible signs but make a very small contribution to explanatory power of the model because of the presence of the individual level past morbidity variables and the age/gender coefficients.

Our focus is on the ten disease management quality measures for general practices. Only the measure for stroke care quality is statistically significant with a coefficient of -0.664 (Table 6, model 1). ${ }^{14}$ We also estimated the cross-section parsimonious model for 2007/8 costs, replacing the current QOF stroke score for 2007/8 with the stroke score for previous years (models 2 to 4 in Table 6). The estimated effect of lagged quality on 2007/8 expenditure is smaller the greater the lag, falling from -0.664 for current stroke quality to -0.322 for $2004 / 5$ stroke quality. ${ }^{15}$

<Table 6 about here>

We undertook robustness checks by forcing the other nine QOF quality measures into models. Model 1 in Table 7 shows the coefficients on the disease domain quality measures when all ten are included in the regression. Three of the coefficients are positive, though not statistically significant, six are negative and statistically insignificant, and only the stroke quality measure is negative and significant. The estimated effect of stroke quality in this model is very similar to its effect when the nine insignificant quality measures are dropped (model 1, Table 6).

$<$ Table 7 about here $>$

\footnotetext{
14 The coefficient on stroke care quality was robust to the nesting down process. The coefficient in the full model with all 250 attributed needs and supply variables was -0.565 (t: -2.23$)$.

${ }^{15}$ Most of the indicators in the clinical domains reflect practice achievement in the 15 months to the financial year end (that is, the QOF indicators for 2007/8 reflect practice achievement from January 2007 to March 2008). This will be slightly (three months) behind of the cost variable which relates to inpatient episodes and outpatient attendances finishing between April 2007 and March 2008.
} 
We also computed an aggregate quality measure as the weighted average of the 10 disease domain measures and found that it is negative and significant when it is included as the only QOF quality measure (Table 7, model 2). The coefficient on the aggregate measure is very similar to that on the stroke score in the earlier model. Finally, we estimated 10 separate models for total hospital cost forcing one of the 10 quality measures into each model. The coefficients from on the quality measures from these 10 separate models are reported in column 3 of Table 7. Four quality measures (asthma, chronic heart disease, diabetes, hypothyroidism) are separately significantly negatively associated with expenditure but the coefficients are smaller and less precise than that on stroke care quality. ${ }^{16}$

In the light of the consistent results from the simple cross-section models we decided to restrict attention in more sophisticated models to the effects of stroke care quality and to use the same parsimonious specification.

\subsection{Two part cross section models}

Table 8 reports estimates of two part models for all hospital expenditures, and for expenditure disaggregated for emergency, elective and outpatient attendances. Higher quality stroke care was significantly associated with a lower probability of any hospital expenditure and reduced hospital expenditure conditional on incurring any expenditure. A 1\% increase in quality was associated with a decrease in the probability of positive expenditures of 0.0002 against a mean probability of 0.309 (elasticity -0.05). A $1 \%$ improvement in stroke care quality was associated with a $£ 2$ reduction in total hospital costs (elasticity -0.12) for those with any costs. We also ran a two part model with log costs and the stroke quality coefficient was -0.0009 (SE 0.0002).

$<$ Table 8 about here $>$

\footnotetext{
${ }^{16}$ We also estimated models with the quality measure constructed using patients reported eligible by the practice $P-E$, rather than those with the disease $P$ (see section 3.2). For the cross section model the coefficient on the stroke quality measure is reduced slightly from -0.644 (SE 0.190) to -0.602 (SE 0.219). The reduction in the estimated coefficient is probably because removing exceptions from the denominator in the quality measure is akin to a rescaling which increases the magnitude of the explanatory variable and hence reduces the magnitude of the coefficient. We also ran models including measures of the share of each practice's admissions at each hospital. The stroke coefficient was again reduced slightly -0.609 (SE 0.219). We tested for robustness to estimation methods by running a cross section GLM model with a log link and gamma distribution for total hospital costs. The coefficient on the stroke quality score was again negative and significant -0.0016 (SE 0.0005).
} 
Higher quality was associated with significantly lower emergency and outpatient visit expenditures, but not with elective costs. The reduction in emergency expenditures was driven by a significant reduction in the probability of admission. A $1 \%$ improvement in stroke quality was associated with a 0.00007 decrease in the probability of emergency admission (elasticity -0.11). There was a negative but insignificant association with emergency expenditure conditional on the patient being admitted. The significant decrease in outpatient expenditures was due to significant reductions in both the probability of a visit (elasticity -0.51) and the cost of visits conditional on any outpatient expenditure (elasticity $-0.01)$.

\subsection{Panel data models}

Results of panel data estimates are presented in Table $9 .{ }^{17}$ Column 1 presents results from a fixed practice effects model. ${ }^{18}$ This estimator controls for unobserved practice-level effects correlated with both quality and expenditure. It relies on variation in QOF scores within practices over time to identify the impact of quality on costs. The estimate of the effect of stroke quality is negative $(-0.091)$, a great deal smaller than the corresponding crosssectional estimate (Table 8, column 1) and not significant. This is likely to reflect the relative lack of variation in practice QOF scores over time compared to the cross-sectional model estimate where the impact of quality is identified through variation across practices. The discrepancy may also reflect the bias in the cross-sectional estimates due to correlation between unobserved practice heterogeneity associated with quality of care and patient costs.

$<$ Table 9 about here $>$

Column 2 is the corresponding random effects specification with a practice-specific error component. The coefficient on the stroke QOF score $(-0.193)$ is smaller than the cross-

\footnotetext{
${ }^{17}$ For the panel models, a $10 \%$ sample of patients registered with each general practice with a list size of at least 1000 at 1 April 2004 was selected $(n=5,131,161)$, and practice registration details along with the LSOA of residence were added for these patients as at 1 April 2005, 1 April 2006, and 1 April 2007. The panel sample thus excludes people born after 1 April 2004 but it includes patients alive at 1 April 2004 but who die at some point during the next four years.

${ }^{18}$ We further attempted individual fixed effects estimation. However, due to a lack of within individual variability in key variables of interest (notably the QOF score) from which to identify parameters, estimation yielded poor and imprecise estimates.
} 
section estimate but larger than the fixed effects estimate in model 1 and is significant at the $1 \%$ level. ${ }^{19}$

Column 3 presents the results of the dynamic panel specification (3) augmented with the individual effect specified as in (4). The coefficient on the stroke QOF score is -0.266 , which is greater than the corresponding coefficient in the random effects model and is significant at the 5\% level. The model controls for individual heterogeneity in costs by directly allowing for persistence over time together with a random GP practice error component. The significant coefficient on lagged cost is 0.125 , so a negative health shock that increases costs in one period will increase future costs but at a rapidly diminishing rate. The coefficient on the initial period individual cost is positive indicating the expected positive correlation between the unobserved individual-specific effects and costs.

Column 4 has results from augmenting the dynamic panel model by including the baseline 2004/5 mean practice cost to provide additional control for practice level heterogeneity. The absolute value of the coefficient on the practice stroke quality score decreases slightly to -0.255 .

We repeat the model in column 4 separately for emergency, elective and outpatient visit costs. The results confirm that the significant association between better quality of practice stroke care and hospital expenditure is driven primarily by prevention of emergency admission and subsequent specialist follow up care than by reductions in elective hospital treatments. The coefficient on lagged costs is much smaller for emergency cost than for outpatient and elective expenditures. suggesting that emergency costs are less persistent. ${ }^{20}$

The mean practice stroke quality increased by ten percentage points between 2004/5 and 2007/8. The average practice population was 5700 so that the RE model dynamic model with baseline individual and mean practice costs (column 4, Table 9) suggests that the improvement in quality of care of stroke patients reduced annual expenditure on the patients of an average practice by $£ 10 * 0.255 * 5700=£ 14,535$ (95\% CI: $-£ 1,464-£ 27,606)$.

\footnotetext{
${ }^{19}$ Using quality measures constructed with P-E rather than P (see section 3.2) for the random practice effects model (model 2 the coefficient is reduced to -0.152 (SE 0.082).

${ }^{20}$ The difference is not due to the relative magnitude of costs in these three categories as average emergency costs exceed average elective and outpatient costs.
} 
Nationally, with an English population in 2007 of 51.1 million, the improvement in stroke care in general practice may have reduced 2007/8 hospital expenditure by £130million (95\% CI: £13.1million -£247million) compared with 2004/5. The significant positive coefficient on one period lagged expenditure (0.125) implies that the total cost saving from a one off increase in $2007 / 8$ stroke quality of $10 \%$ which reduced total $2008 / 9$ cost by $£ 130$ million should also include a reduction in 2008/9 expenditure of $0.125 * £ 130$ million $=£ 16$ million.

\section{Conclusions}

This study has taken advantage of a major new data set that links practice-based patient registration data, patient level hospital use data, and GP practice clinical quality data to examine whether higher quality of disease management in primary care is associated with reduced hospital costs. Applying cross-section and panel data methods to a data set of 5 million individuals, with a very rich set of covariates, we find that the current QOF stroke quality score almost always has a statistically significant negative association with patients' hospital costs in the same year. Once stroke quality was allowed for, hospital costs were not affected by the quality of primary care disease management for any of the other nine conditions for which we had data.

The reduction in total hospital expenditure associated with better quality of practice stroke care is due primarily to a reduction in the probability of emergency hospitalization and in outpatient visits. There were negative but small and insignificant associations between quality and elective expenditure, which suggests that better monitoring of patients has not lead to increased costs arising from increased referrals by GPs to secondary care. Since we measure costs for all patients in practices, not just those whose disease management was incentivized under the QOF, our estimates allow for the possibility of diversion of preventive efforts in primary care away from other primary care patients. There was also significant persistence over time in secondary care medical costs indicating the longer term importance of better disease management. There are weaker, but still statistically significant associations of 2007/8 hospital costs with general practice stroke quality in earlier years. The study demonstrates the importance of using panel data methods to control for unobserved patient and practice heterogeneity in non-randomized studies when assessing the impact of quality of care on patient outcomes. 
Whilst we suggest a modest association between this aspect of primary care disease management and hospital costs, we so not claim that improved primary care will reduce lifetime health care costs. As is well-known, the majority of disease prevention strategies generate additional costs (Cohen et al, 2008). Our focus is solely on the annual impact on contemporaneous secondary care costs when there is an improvement in primary care prevention. We do not consider, for example, the $£ 1$ billion paid to general practices for their QOF achievements, nor the additional pharmaceutical and primary care costs associated with meeting QOF stroke targets, nor the impact on total lifetime healthcare costs if the patient lives longer as a result of better primary care. Ideally a full evaluation would use measures of disease management quality for individuals rather than at the practice level as in this paper and would also incorporate data on morbidity from practice records, rather than from just from hospital records. A full evaluation of primary care disease management must also take account of its effect on the future time stream of health and on costs. But the reduction in hospital costs due to better primary care disease management is part of the gains to be included in the evaluation.

In summary, we are cautious about drawing inferences of causality from our analysis, but feel that the panel data results do offer solid grounds for believing that improvements in primary care disease management do not increase hospital costs, and that for at least some conditions, better management materially reduces hospital costs. 


\section{References}

Agency for Healthcare Quality and Research. 2004. AHRQ Quality Indicators - Guide to Prevention Quality Indicators: Hospital Admission for Ambulatory Care Sensitive Conditions. Rockville, MD: Pub. No. 02-R0203. Available at http://www.qualityindicators.ahrq.gov/pqi_download.htm

Blundell, R., Griffith, R., Van Reenen, J. (1999). Market share, market value and innovation in a panel of British manufacturing firms. The Review of Economic Studies 66, 529-554.

Blundell, R., Grifith, R., Windmeijer, F. (2002). Individual effects and dynamics in count data Models. Journal of Econometrics 108, 113-131.

Bottle A, Gnani S, Saxena S, Aylin P, Mainous A, Majeed A. (2008). Association between quality of primary care and hospitalization for coronary heart disease in England: a national cross-sectional study. J Gen Intern Medicine, 23, 135-141.

Bottle A, Millett C, Xie Y, Saxena S, Wachter R, Majeed A. (2008). Quality of primary care and hospital admissions for diabetes mellitus in England. Journal of Ambulatory Care Management, 31, 226-238.

Briscoe, V., Davis, S. (2006). Hypoglycemia in type I and type II diabetes: physiology, pathophysiology, and management. Clinical Diabetes, 24(3), 115-121

de Bruin S.R., Heijink R., Lemmens L. C., Struijs J.N., Baan C. A.. (2011). Impact of disease management programs on healthcare expenditures for patients with diabetes, depression, heart failure or chronic obstructive pulmonary disease: A systematic review of the literature. Health Policy 101 105- 121.

Bruni, M., L. Nobilio, C. Ugolini. (2009). Economic incentives in general practice: the impact of pay-for-participation and pay-for-compliance programs on diabetic care. Health Policy 90: 140-148.

Buntin, M.B., Zaslavsky, A.M. (2004). Too much ado about two-part models and transformation? Comparing methods of modeling Medicare expenditures. Journal of Health Economics, 23: 525-542.

Calderón-Larrañaga A., Carney L, Soljak M, Bottle A, Partridge M, Bell D, Abi-Aad G, Aylin P, and Majeed A. (2011) Association of population and primary healthcare factors with hospital admission rates for chronic obstructive pulmonary disease in England: national cross sectional study. Thorax; 66: 191-6

Chen, J. Y., Tian, H., Taira. J. D., Hodges, K. A., Brand J. C., Chung, R. S., Legorreta, A. P. 2010. The Effect of a PPO Pay-for-Performance Program on Patients With Diabetes. The American Journal of Managed Care, vol. 16, no. 1.

Cohen J, Neumann P, Weinstein M. (2008). Does preventive care save money? Health economics and the presidential candidates. New England Journal of Medicine 358: 661-664. 
Congressional Budget Office (2004), An Analysis of the Literature on Disease Management Programs, Washington DC: Congressional Budget Office.

Department of Health (2004). Quality and outcomes framework guidance - updated August 2004.

Dixon J, Bardsley M, Georghiou T, Steventon A, Smith P, Gravelle H, Martin S, Dusheiko M, Rice N, Billings J, Delorenzo M, Russell R, Filipova N, Sanderson C (2009). Developing a person based resource allocation formula for allocations to general practices in England. Report to the Department of Health.

Doran T. (2008). Lessons from early experience with pay for performance. Disease Management and Health Outcomes, 16(2), 69-77.

Doran T, Fullwood C, Gravelle H, Reeves D, Kontopantelis E, Hiroeh U, Roland M. (2006). Pay for performance programs in family practices in the United Kingdom. New England Journal of Medicine, 355, 375-384.

Doran, T., Fullwood, C., Gravelle, H., Reeves, D. and Roland M. (2008). Exclusion of patients from pay-for-performance targets by English physicians. New England Journal of Medicine, 2008, 359, 274-284.

Downing A, Rudge G, Cheng Y, Tu Y, Keen J, Gilthorpe M. (2007). Do the UK government's new Quality and Outcomes Framework (QOF) scores adequately measure primary care performance? A cross-sectional survey of routine healthcare data. BMC Health Services Research, 7, 166.

Dunn, G., Mirandola, M., Amaddeo, F., Tansella, M. (2003). Describing, explaining or predicting mental health cares: a guide to regression models. British Journal of Psychiatry, 183: 398-404.

Dusheiko, M., Doran, T., Gravelle, H., Fullwood, C., Roland, M., (2010a). Does Higher Quality of Diabetes Management in Family Practice Reduce Unplanned Hospital Admissions?Health Services Research, in press., Forthcoming. DOI: 10.1111/j.14756773.2010.01184.x

Dusheiko M, Gravelle H, Martin S, Rice N, Smith PC. (2011). Disease management in primary care and patients' hospital costs in England. Centre for Health Economics Research Paper. http://www.york.ac.uk/inst/che/

Ellis, R. P., McGuire, T. G. (2007). Predictability and predictiveness in health care spending. Journal of Health Economics 26:25-48.

Gravelle H, Sutton M, Ma A. (2010). Doctor behaviour under a pay for performance contract: treating, cheating and case finding? Economic Journal., 2010, 120, F129-F156.

HSCIC (2005). National Quality and Outcomes Framework Statistics for England 2004/05. NHS Health and Social Care Information Centre.

HSCIC (2007). National Quality and Outcomes Framework Statistics for England 2006/07. 
NHS Health and Social Care Information Centre.

Contoyannis, P., Jones, A.M., Rice, N. (2004). The dynamics of health in the British Household Panel Survey. Journal of Applied Econometrics. 19: 473-503.

Fiorentini, G., Iezzi, E., Bruni, M. L., Ugolini, C. 2010. Incentives in primary care and their impact on potentially avoidable hospital admissions. European Journal of Health Econonomics, DOI 10.1007/s10198-010-0230-X.

Kiran, T., Hutchings, A., Dhalla, I.A., Furlong C., Jacobson, B. (2010). The association between quality of primary care, deprivation and cardiovascular outcomes a cross-sectional study using data from the UK Quality and Outcomes Framework. Journal of Epidemiol Community Health doi:10.1136/jech.2009.098806.

Lee, T., S. Cheng, C. Chen, and M. Lai. (2010). A pay-for-performance program for diabetes care in Taiwan: a preliminary assessment. American Journal of Managed Care 16: 65-69.

Lester. H., Schmittdiel J., Selby. J., Fireman, B., Campbell, S., Lee, J., Whippy, A., Madvi, P. (2010). The impact of removing financial incentives from clinical quality indicators: longitudinal analysis of four Kaiser Permanente indicators. British Medical Journal 340:c1898.

Manca, A., Hawkins N., Sculpher, M., J. (2005), Estimating mean QALYs in trial-based costeffectivenessanalysis: the importance of controlling for baseline utility. Health Economics 14: 487-496.

Manning WG, Basu A, Mullahy J. (2005) Generalized modeling approaches to risk adjustment of skewed outcomes. Journal of Health Economics; 24:465-488.

Mullen, K. J., Frank, R. G.., Rosenthal, M. B. (2010). Can you get what you pay for? Pay-for-performance and the quality of healthcare providers. RAND Journal of Economics Vol. 41, No. 1, Spring 2010 pp. 64-91.

Mundlak, Y. (1978). On the pooling of time series and cross-section data. Econometrica, 46: 69-85.

National Audit Office (2008). NHS Pay Modernisation: New Contracts for General Practice Services in England. London: The Stationery Office.

NHS Employers (no date). Revisions to the GMS Contract 2006/7. http://www.nhsemployers.org/SiteCollectionDocuments/Revisions_to_the_GMS_contract_full_CD_120209.pdf Accessed 18 June 2010.

PBRA Team. (2010). Developing a person based resource allocation formula for allocations to general practices in England. http://www.nuffieldtrust.org.uk/our-work/projects/personbased-resource-allocation-pbra

Purdy, S., T. Griffin, C. Salisbury, D. Sharp. (2009). Ambulatory care sensitive conditions: terminology and disease coding need to be more specific to aid policy makers and clinicians. Public Health, 123, 169-173. 
Purdy, S., T. Griffin, C. Salisbury, and D. Sharp. (2011) Ambulatory care sensitive conditions: terminology and disease coding need to be more specific to aid policy makers and clinicians. Public Health; 123: 169-173.

Roland M. (2004). Linking physician pay to quality of care: a major experiment in the UK. New England Journal of Medicine, 351, 1448-54.

Russell, L. B. (2009). Preventing Chronic Disease: An Important Investment, But Don't Count On Cost Savings. Health Affairs, 28(1), $42-45$.

Scott, A., S. Schurer, P. H. Jensen, P. Sivey. (2009). The effects of an incentive program on quality of care in diabetes management. Health Economics 18: 1091-1108.

Shohet C, Yelloly J, Bingham P, Lyratzopoulos G. (2007). The association between the quality of epilepsy management in primary care, general practice population deprivation status and epilepsy-related emergency admissions. Seizure, 16, 351-355.

Sutton, M., Dixon, P. and Morris, S. (2007). Review of Need Formula 2006/7: Individual level models. Report prepared for ACRA, Department of Health. 
Table 1. Costs and use for $2007 / 8$

\begin{tabular}{lccccc}
\hline & $\begin{array}{c}\text { All hospital } \\
\text { use }\end{array}$ & $\begin{array}{c}\text { Emergency } \\
\text { inpatient }\end{array}$ & $\begin{array}{c}\text { Elective } \\
\text { inpatient }\end{array}$ & Outpatient & Other \\
\hline Average cost (sd) for all & 427 & 150 & 144 & 119 & 14 \\
patients $(£)$ & $(2,067)$ & $(1,086)$ & $(1,338)$ & $(451)$ & $(410)$ \\
Probability of positive cost & $30.85 \%$ & $5.54 \%$ & $7.55 \%$ & $28.74 \%$ & $0.30 \%$ \\
Average cost (sd) for patients & 1,383 & 2,707 & 1,904 & 414 & 4,710 \\
with positive cost $(£)$ & $(3,539)$ & $(3,791)$ & $(4,513)$ & $(765)$ & $(5,818)$ \\
\hline
\end{tabular}

Notes. For random sample of 5,170,603 patients on lists of English practices with at least 1000 patients at 1 April 2007. Excludes maternity and mental health. The "Other" category includes patients transferred between hospitals and where the admission method is not known.

Table 2. QOF indicators used to construct measure of practice quality of care for stroke patients

\begin{tabular}{|c|c|c|c|}
\hline & & $\begin{array}{c}\text { Upper } \\
\text { threshold }\end{array}$ & $\begin{array}{l}\text { Available } \\
\text { points }\end{array}$ \\
\hline STROKE 5 & $\begin{array}{l}\text { \% who have a record of blood pressure in the notes in } \\
\text { the preceding } 15 \text { months }\end{array}$ & 90 & 2 \\
\hline STROKE 6 & $\begin{array}{l}\% \text { in whom the last blood pressure reading (measured } \\
\text { in the last } 15 \text { months) is } 150 / 90 \text { or less }\end{array}$ & 70 & 5 \\
\hline STROKE 7 & $\begin{array}{l}\% \text { who have a record of total cholesterol in the last } 15 \\
\text { months }\end{array}$ & 90 & 2 \\
\hline STROKE 8 & $\begin{array}{l}\% \text { whose last measured total cholesterol (measured in } \\
\text { the last } 15 \text { months) is } 5 \mathrm{mmol} / \mathrm{l} \text { or less }\end{array}$ & 60 & 5 \\
\hline STROKE 10 & $\begin{array}{l}\% \text { who have had influenza immunisation in the } \\
\text { preceding } 1 \text { September to } 31 \text { March }\end{array}$ & 85 & 2 \\
\hline STROKE 12 & $\begin{array}{l}\text { \%who have a record that an anti-platelet agent } \\
\text { (aspirin, clopidogrel, dipyridamole or a combination), } \\
\text { or an anti-coagulant is being taken (unless a } \\
\text { contraindication or side-effects are recorded }\end{array}$ & 90 & 4 \\
\hline
\end{tabular}

Notes. TIA: transient ischemic attack. For '\%' read 'the percentage of patients'. Indicators Stroke 5 to Stroke 12 have lower payment thresholds of 40\%. Source: NHS Employers (no date) . 
Table 3. Disease domains in the Quality and Outcomes Framework 2007/8 used to construct general practice disease management quality measures

\begin{tabular}{lrr}
\hline & $\begin{array}{r}\text { Number of } \\
\text { indicators in } \\
\text { measure }\end{array}$ & $\begin{array}{r}\text { Total points } \\
\text { available }\end{array}$ \\
\hline Asthma & 2 & 35 \\
CHD & 9 & 85 \\
CKD & 3 & 21 \\
COPD & 4 & 30 \\
Dementia & 1 & 15 \\
Diabetes & 15 & 87 \\
Hypertension & 2 & 77 \\
Hypothyroidism & 1 & 6 \\
Mental health & 5 & 35 \\
Stroke & 6 & 20 \\
Total & 48 & 411 \\
\hline Not. Sorce: NHE Employ
\end{tabular}

Notes. Source: NHE Employers (no date). CHD: coronary heart disease; CKD: chronic kidney disease; COPD: chronic obstructive pulmonary disease. Note: not all indicators were used to construct our composite quality scores (see section 3 for further details).

Table 4. Descriptive statistics for general practice disease management quality measures 2007/8

\begin{tabular}{lccccc}
\hline QOF quality measure & $\begin{array}{c}\text { Number of } \\
\text { practices }\end{array}$ & \multicolumn{3}{c}{ Weighted average population } \\
& & Mean & SD & Min & Max \\
\hline Asthma & 8289 & 76.38 & 9.11 & 0.00 & 100 \\
CHD & 8284 & 82.74 & 3.85 & 35.00 & 100 \\
CKD & 8251 & 97.68 & 2.57 & 50.00 & 100 \\
COPD & 8279 & 81.97 & 8.61 & 0.00 & 100 \\
Dementia & 8200 & 75.44 & 17.48 & 0.00 & 100 \\
Diabetes & 8290 & 87.42 & 5.57 & 9.38 & 100 \\
Hypertension & 8292 & 91.28 & 4.11 & 14.87 & 100 \\
Hypothyroidism & 8281 & 95.37 & 3.78 & 9.09 & 100 \\
Mental health & 8284 & 74.73 & 13.66 & 0.00 & 100 \\
Stroke & 8276 & 86.17 & 5.77 & 6.67 & 100 \\
\hline
\end{tabular}

Notes: population achievement for an indicator $i$ in disease domain $k$ is defined as $N_{i k} /\left(P_{k}-E_{i k}\right)$ where $N_{i k}$ is the number of patients for whom the indicator is achieved, $P_{k}$ is the number of patients with the disease, $E_{i k}$ is the number of patients with the disease who are exception reported. The quality measure for a disease domain is a weighted average of population achievement on each indicator in the domain, where the weights are the maximum points available for the indicator. 
Table 5. Correlation coefficients for general practice disease management quality measures 2007/8

\begin{tabular}{|c|c|c|c|c|c|c|c|c|c|}
\hline & Asthma & CHD & CKD & COPD & Dementia & Diabetes & $\begin{array}{l}\text { Hyper- } \\
\text { tension }\end{array}$ & $\begin{array}{c}\text { Hypo- } \\
\text { thyroidism }\end{array}$ & $\begin{array}{l}\text { Mental } \\
\text { Health }\end{array}$ \\
\hline CHD & 0.349 & & & & & & & & \\
\hline CKD & 0.212 & 0.266 & & & & & & & \\
\hline COPD & 0.356 & 0.485 & 0.194 & & & & & & \\
\hline Dementia & 0.257 & 0.216 & 0.129 & 0.226 & & & & & \\
\hline Diabetes & 0.368 & 0.536 & 0.245 & 0.484 & 0.218 & & & & \\
\hline Hypertension & 0.406 & 0.476 & 0.336 & 0.373 & 0.229 & 0.489 & & & \\
\hline Hypothyroidism & 0.272 & 0.368 & 0.210 & 0.296 & 0.179 & 0.400 & 0.455 & & \\
\hline Mental Health & 0.329 & 0.210 & 0.137 & 0.225 & 0.285 & 0.212 & 0.213 & 0.110 & \\
\hline Stroke & 0.343 & 0.607 & 0.301 & 0.466 & 0.225 & 0.530 & 0.484 & 0.371 & 0.234 \\
\hline
\end{tabular}

Note: the number of practices is 8,178 . 
Table 6. Association of general practice stroke management quality with $2007 / 8$ hospital expenditure: cross section models

\begin{tabular}{|c|c|c|c|c|}
\hline & 1 & 2 & 3 & 4 \\
\hline Stroke $2007 / 8$ & $\begin{array}{l}-0.664 * * * \\
{[0.190]}\end{array}$ & & & \\
\hline Stroke 2006/7 & & $\begin{array}{l}-0.531 * * * \\
{[0.169]}\end{array}$ & & \\
\hline Stroke 2005/6 & & & $\begin{array}{l}-0.460 * * * \\
{[0.145]}\end{array}$ & \\
\hline Stroke 2004/5 & & & & $\begin{array}{r}-0.322 * * \\
{[0.124]}\end{array}$ \\
\hline Observations & 5170603 & 5170603 & 5170603 & 5166983 \\
\hline $\mathrm{R}^{2}$ & 0.265 & 0.265 & 0.265 & 0.265 \\
\hline
\end{tabular}

Notes: Dependent variable: patient hospital expenditure in 2007/8. Reported coefficients are effect of a $1 \%$ increase in clinical population achievement in a patient's practice on the patient's hospital expenditure. Robust standard errors in brackets with clustering by PCT.

All models also contain 37 age/gender bands, 152 ICD10 morbidity dummies for 2006/7 and 2005/6, 4 hospital encounter variables for 2006/7, 2005/6, 2 private patient measures for 2006/7 and 2005/6, 5 attributed needs variables, 151 PCT dummies. See Sections 2 and 3 for details. ${ }^{* *} \mathrm{p}<0.01,{ }^{* *} \mathrm{p}<0.05,{ }^{*} \mathrm{p}<0.1$ 
Table 7. Association of $\mathbf{2 0 0 7 / 8}$ general practice disease management quality measures with 2007/8 hospital costs

\begin{tabular}{|c|c|c|c|}
\hline & $\begin{array}{c}1 \\
\text { All } \\
\text { quality } \\
\text { measures } \\
\text { in single } \\
\text { regression }\end{array}$ & $\begin{array}{c}2 \\
\text { Overall } \\
\text { quality }\end{array}$ & $\begin{array}{c}3 \\
\text { Quality } \\
\text { measures } \\
\text { entered in } \\
\text { separate } \\
\text { regressions }\end{array}$ \\
\hline Asthma & $\begin{array}{c}-0.153 \\
{[0.127]}\end{array}$ & & $\begin{array}{l}-0.241^{* *} \\
{[0.099]}\end{array}$ \\
\hline Coronary heart disease & $\begin{array}{c}-0.028 \\
{[0.385]}\end{array}$ & & $\begin{array}{l}-0.637^{* * *} \\
{[0.297]}\end{array}$ \\
\hline Chronic kidney disease & $\begin{array}{l}-0.013 \\
{[0.437]}\end{array}$ & & $\begin{array}{l}-0.442 \\
{[0.395]}\end{array}$ \\
\hline COPD & $\begin{array}{c}0.099 \\
{[0.180]}\end{array}$ & & $\begin{array}{l}-0.158 \\
{[0.152]}\end{array}$ \\
\hline Dementia & $\begin{array}{l}-0.039 \\
{[0.062]}\end{array}$ & & $\begin{array}{c}-0.090 \\
{[0.059]}\end{array}$ \\
\hline Diabetes & $\begin{array}{c}0.037 \\
{[0.237]}\end{array}$ & & $\begin{array}{l}-0.374^{* *} \\
{[0.182]}\end{array}$ \\
\hline Hypertension & $\begin{array}{c}0.462 \\
{[0.376]}\end{array}$ & & $\begin{array}{c}-0.213 \\
{[0.251]}\end{array}$ \\
\hline Hypothyroidism & $\begin{array}{l}-0.387 \\
{[0.438]}\end{array}$ & & $\begin{array}{l}-0.657^{*} \\
{[0.372]}\end{array}$ \\
\hline Mental health & $\begin{array}{c}-0.046 \\
{[0.077]}\end{array}$ & & $\begin{array}{c}-0.115 \\
{[0.072]}\end{array}$ \\
\hline Stroke & $\begin{array}{l}-0.666^{* *} \\
{[0.258]}\end{array}$ & & $\begin{array}{c}-0.664^{* * *} \\
{[0.190]}\end{array}$ \\
\hline Overall quality & & $\begin{array}{c}-0.698^{* * *} \\
{[0.236]}\end{array}$ & \\
\hline $\begin{array}{l}\text { Observations } \\
\mathrm{R}^{2}\end{array}$ & $\begin{array}{c}5,170,603 \\
{[0.265]}\end{array}$ & $\begin{array}{l}5,170,603 \\
{[0.265]}\end{array}$ & $5,170,603$ \\
\hline
\end{tabular}

Notes: Dependent variable in all models is 2007/8 hospital expenditure. Reported coefficients are effect of a $1 \%$ increase in clinical population achievement in a patient's practice on the patient's hospital expenditure. Robust standard errors in brackets with clustering by PCT. All models are cross section and also contain 37 age/gender bands, 152 ICD10 morbidity dummies for 2006/7 and 2005/6, 4 hospital encounter variables for 2006/7, 2005/6, 2 private patient measures for 2006/7 and 2005/6, 5 attributed needs variables, 151 PCT dummies. (See Sections 3 and 4 for details.) All 10 models reported in column 3 had the same $\mathrm{R}^{2}$ of 0.265 .

$* * * \mathrm{p}<0.01, * * \mathrm{p}<0.05, * \mathrm{p}<0.1$ 
Table 8. Association of general practice stroke management quality with costs and use for different types of hospital cost, 2007/8

\begin{tabular}{|c|c|c|c|c|c|c|c|c|c|c|c|c|}
\hline & 1 & 2 & 3 & 4 & 5 & 6 & 7 & 8 & 9 & 10 & 11 & 12 \\
\hline & \multicolumn{3}{|c|}{ All hospital use } & \multicolumn{3}{|c|}{ Emergency admissions } & \multicolumn{3}{|c|}{ Elective admissions } & \multicolumn{3}{|c|}{ Outpatient visits } \\
\hline & $\begin{array}{c}\text { Total cost } \\
\text { (OLS) }\end{array}$ & $\begin{array}{l}\text { Part } 1 \\
\text { Prob use } \\
\text { (probit) }\end{array}$ & $\begin{array}{c}\text { Part } 2 \\
\text { Cost if use } \\
\text { (OLS) }\end{array}$ & $\begin{array}{l}\text { Total cost } \\
\text { (OLS) }\end{array}$ & $\begin{array}{c}\text { Part } 1 \\
\text { Prob } \\
\text { admission } \\
\text { (probit) }\end{array}$ & $\begin{array}{c}\text { Part } 2 \\
\text { Cost if } \\
\text { admitted } \\
(\text { OLS })\end{array}$ & $\begin{array}{l}\text { Total cost } \\
\text { (OLS) }\end{array}$ & $\begin{array}{c}\text { Part } 1 \\
\text { Prob } \\
\text { admission } \\
\text { (probit) }\end{array}$ & $\begin{array}{c}\text { Part } 2 \\
\text { Cost if } \\
\text { admitted } \\
\text { (OLS) }\end{array}$ & $\begin{array}{c}\text { Total cost } \\
\text { (OLS) }\end{array}$ & $\begin{array}{l}\text { Part } 1 \\
\text { Prob visit } \\
\text { (probit) }\end{array}$ & $\begin{array}{l}\text { Part } 2 \\
\text { Cost if visit } \\
\text { (OLS) }\end{array}$ \\
\hline $\begin{array}{c}\text { Stroke QOF } \\
\text { score } \\
\text { coefficient }\end{array}$ & $\begin{array}{c}-0.664 * * * \\
{[0.190]}\end{array}$ & $\begin{array}{c}-0.00066 * * \\
{[0.00026]}\end{array}$ & $\begin{array}{c}-1.996 * * * \\
{[0.602]}\end{array}$ & $\begin{array}{c}-0.319 * * * \\
{[0.096]}\end{array}$ & $\begin{array}{c}-0.00071^{* * *} \\
{[0.00026]}\end{array}$ & $\begin{array}{c}-1.970 \\
{[1.431]}\end{array}$ & $\begin{array}{c}-0.089 \\
{[0.113]}\end{array}$ & $\begin{array}{c}-0.00042 \\
{[0.00027]}\end{array}$ & $\begin{array}{c}-1.406 \\
{[1.324]}\end{array}$ & $\begin{array}{c}-0.164^{* *} \\
{[0.063]}\end{array}$ & $\begin{array}{c}-0.00061 * * \\
{[0.00026]}\end{array}$ & $\begin{array}{c}-0.400 * * \\
{[0.197]}\end{array}$ \\
\hline $\begin{array}{c}\text { Av marginal } \\
\text { effect }\end{array}$ & & $\begin{array}{c}-0.00019 * * \\
{[0.00007]}\end{array}$ & & & $\begin{array}{c}-0.00007 * * * \\
{[0.000025]}\end{array}$ & & & $\begin{array}{c}-0.000052 \\
{[0.000034]}\end{array}$ & & & $\begin{array}{c}-0.0017^{* *} \\
{[0.00007]}\end{array}$ & \\
\hline $\mathrm{N}$ & $5,170,603$ & $5,170,603$ & $1,595,303$ & $5,170,603$ & $5,170,603$ & 286,629 & $5,170,603$ & $5,170,603$ & 390,245 & $5,170,603$ & $5,170,603$ & $1,486,211$ \\
\hline $\mathrm{R}^{2}$ & 0.2654 & 0.1940 & 0.2502 & 0.0986 & 0.1314 & 0.1421 & 0.0977 & 0.1276 & 0.3943 & 0.2062 & 0.1929 & 0.0936 \\
\hline
\end{tabular}

Notes: All models are cross section and also contain 37 age/gender bands, 152 ICD10 morbidity dummies for 2006/7 and 2005/6, 4 hospital encounter variables for 2006/7, 2005/6, 2 private patient measures for 2006/7 and 2005/6, 5 attributed needs variables, and 151 PCT dummies. See Sections 2 and 3 for details. The R ${ }^{2}$ is a pseudo-Rsquared for the probit models. $* * * \mathrm{p}<0.01, * * \mathrm{p}<0.05$, * $\mathrm{p}<0.1$. 
Table 9. Panel data models for patient hospital costs 2004/5 - 2007/8

\begin{tabular}{|c|c|c|c|c|c|c|c|}
\hline & $\begin{array}{c}1 \\
\text { fixed practice } \\
\text { effects } \\
\text { all costs }\end{array}$ & \begin{tabular}{c}
\multicolumn{1}{c}{2} \\
random \\
practice \\
effects \\
all costs
\end{tabular} & \begin{tabular}{c}
\multicolumn{1}{c}{3} \\
random \\
practice \\
effects \\
all costs
\end{tabular} & \begin{tabular}{c}
\multicolumn{1}{c}{4} \\
random \\
practice \\
effects \\
all costs
\end{tabular} & $\begin{array}{c}5 \\
\text { random } \\
\text { practice } \\
\text { effects } \\
\text { emergency } \\
\text { costs only }\end{array}$ & $\begin{array}{c}6 \\
\text { random } \\
\text { practice } \\
\text { effects } \\
\text { elective costs } \\
\text { only }\end{array}$ & $\begin{array}{c}7 \\
\text { random } \\
\text { practice } \\
\text { effects } \\
\text { outpatient } \\
\text { costs only }\end{array}$ \\
\hline stroke QOF score & $\begin{array}{c}-0.091 \\
{[0.135]}\end{array}$ & $\begin{array}{c}-0.193 * * \\
{[0.085]}\end{array}$ & $\begin{array}{c}-0.266^{* *} \\
{[0.117]}\end{array}$ & $\begin{array}{c}-0.255^{* *} \\
{[0.117]}\end{array}$ & $\begin{array}{c}-0.245^{* * *} \\
{[0.078]}\end{array}$ & $\begin{array}{c}0.072 \\
{[0.065]}\end{array}$ & $\begin{array}{c}-0.058 * * \\
{[0.026]}\end{array}$ \\
\hline lagged individual cost & & & $\begin{array}{c}0.125^{* * *} \\
{[0.005]}\end{array}$ & $\begin{array}{c}0.125^{* * *} \\
{[0.005]}\end{array}$ & $\begin{array}{c}0.053 * * * \\
{[0.002]}\end{array}$ & $\begin{array}{c}0.205^{* * *} \\
{[0.011]}\end{array}$ & $\begin{array}{c}0.558 * * * \\
{[0.030]}\end{array}$ \\
\hline base individual cost & & & $\begin{array}{c}0.016^{* * *} \\
{[0.005]}\end{array}$ & $\begin{array}{c}0.016^{* * *} \\
{[0.005]}\end{array}$ & $\begin{array}{c}0.046^{* * *} \\
{[0.003]}\end{array}$ & $\begin{array}{c}0.013 \\
{[0.011]}\end{array}$ & $\begin{array}{c}0.088 * * * \\
{[0.015]}\end{array}$ \\
\hline base practice cost & & & & $\begin{array}{c}0.032^{* * *} \\
{[0.007]}\end{array}$ & $\begin{array}{c}0.024^{* * *} \\
{[0.008]}\end{array}$ & $\begin{array}{c}0.023^{* *} \\
{[0.009]}\end{array}$ & $\begin{array}{c}0.105^{* * *} \\
{[0.007]}\end{array}$ \\
\hline Observations (NT) & $19,701,431$ & $19,701,431$ & $14,590,999$ & $14,590,999$ & $14,590,999$ & $14,590,999$ & $14,590,999$ \\
\hline Individuals (N) & $5,123,157$ & $5,123,157$ & $5,005,347$ & $5,005,347$ & $5,005,347$ & $5,005,347$ & $5,005,347$ \\
\hline Within $\mathrm{R}^{2}$ & 0.2047 & 0.2031 & 0.2091 & 0.2091 & 0.0691 & 0.2825 & 0.2937 \\
\hline Between $\mathrm{R}^{2}$ & $\mathrm{n} / \mathrm{a}$ & 0.7414 & 0.7007 & 0.7006 & 0.5508 & 0.6644 & 0.8632 \\
\hline Overall $\mathrm{R}^{2}$ & $\mathrm{n} / \mathrm{a}$ & 0.2043 & 0.2103 & 0.2103 & 0.0699 & 0.2832 & 0.2979 \\
\hline
\end{tabular}

Note: The dependent variable in all models is individual hospital cost in a year. Model 1 is a fixed (practice) effects model with robust standard errors clustered by general practice. Model 2 is a random (practice) effects model with robust standard errors clustered by practice. Model 3 is the same as model 2 with the addition of lagged

individual cost and baseline individual cost. Model 4 is the same as model 3 with the addition of baseline practice cost. Models $5-7$ are the same as model 4 but employ a different measure of cost as the dependent variable and as regressors. All models also contain 37 age/gender bands, 152 ICD10 morbidity dummies, 4 hospital encounter variables, 2 private patient measures, 5 attributed needs variables, 3 year dummies and 151 PCT dummies. See Sections 2 and 3 for details. ${ }^{* * *} \mathrm{p}<0.01$, ${ }^{* *} \mathrm{p}<0.05,{ }^{*} \mathrm{p}<0.1$. 
Appendix A1: Summary of modelling results

Determinants of individual hospital costs

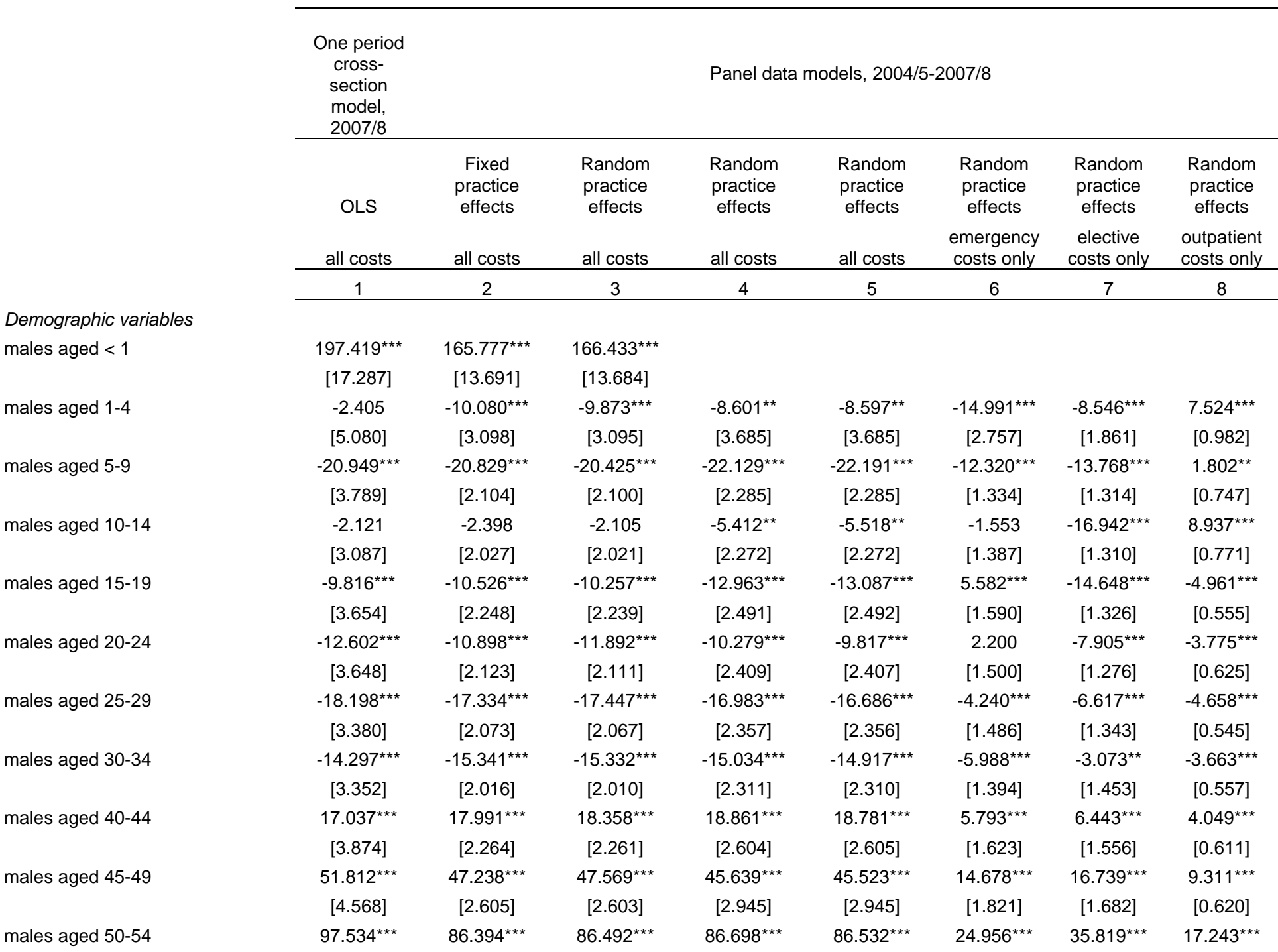


males aged 55-59

males aged 60-64

males aged 65-69

males aged 70-74

males aged $75-79$

males aged $80-84$

males aged over 85

females aged $<1$

females aged 1-4

females aged 5-9

females aged 10-14

females aged 15-19

females aged 20-24

females aged 25-29

females aged 30-34

females aged 35-39

females aged 40-44

\begin{tabular}{|c|c|c|c|c|c|c|c|}
\hline [5.971] & [3.010] & [3.007] & [3.435] & [3.435] & [2.082] & [2.078] & [0.750] \\
\hline $158.800^{\star \star \star}$ & $158.851^{\star \star \star}$ & $159.115^{\star \star \star}$ & $158.972^{\star * \star}$ & $158.763^{\star \star \star}$ & $44.319^{\star \star \star}$ & $73.653^{\star \star \star}$ & $28.233^{\star \star \star}$ \\
\hline [5.513] & [3.378] & [3.376] & [3.860] & [3.860] & [2.382] & [2.397] & {$[0.757]$} \\
\hline $256.885^{\star \star \star}$ & $257.573^{\star \star \star}$ & $257.563^{\star \star \star}$ & $253.905^{\star \star \star}$ & $253.651^{\star \star \star}$ & $75.854^{\star \star \star}$ & $114.211^{\star \star *}$ & $43.510^{\star * \star}$ \\
\hline [7.790] & [4.201] & [4.199] & [4.812] & [4.813] & [3.030] & [2.961] & [0.964] \\
\hline $372.892^{\star \star \star}$ & $388.696^{\star \star \star}$ & $388.242^{\star \star \star}$ & $384.364^{\star * *}$ & $384.076^{\star \star \star}$ & $122.706^{\star \star \star}$ & $170.182^{\star \star \star}$ & $60.646^{\star \star *}$ \\
\hline [10.292] & [5.628] & [5.627] & [6.359] & [6.358] & [3.900] & [4.186] & [1.059] \\
\hline $543.605^{\star \star \star}$ & $554.111^{\star \star \star}$ & $553.779^{\star \star \star \star}$ & $544.812^{\star \star \star}$ & 544.476 *** & $217.906^{\star \star \star}$ & $209.371^{\star \star \star}$ & $77.231^{\star \star \star}$ \\
\hline [10.572] & [6.862] & [6.858] & [7.874] & [7.872] & [5.170] & [4.778] & [1.256] \\
\hline $665.427^{\star \star \star}$ & $723.810^{\star \star \star *}$ & $723.210^{\star \star \star *}$ & $719.482^{\star \star *}$ & $719.098^{\star \star \star}$ & $354.787^{\star \star *}$ & $227.876^{\star \star \star}$ & $88.193^{\star \star \star}$ \\
\hline [17.597] & [8.466] & [8.462] & [9.880] & [9.881] & [6.807] & [5.785] & [1.445] \\
\hline $849.446^{\star \star \star}$ & $893.550^{\star \star \star}$ & $892.651^{\star \star \star}$ & 899.530 *** & $899.111^{\star \star \star}$ & $580.771^{\star \star *}$ & $186.437^{\star \star \star}$ & $80.618^{\star \star \star}$ \\
\hline [21.208] & [11.342] & [11.345] & [13.266] & [13.265] & [9.437] & [7.498] & [1.521] \\
\hline $1,054.627^{\star \star \star}$ & $1,100.922^{\star * \star}$ & $1,100.030^{\star * \star}$ & $1,110.798^{\star * \star}$ & $1,110.323^{\star \star \star}$ & $904.912^{\star \star \star}$ & $95.547^{\star \star \star}$ & $53.821^{\star * *}$ \\
\hline [26.048] & [13.845] & [13.847] & [15.887] & [15.889] & [13.320] & [6.495] & [1.510] \\
\hline $138.289^{\star \star \star}$ & $99.636^{\star \star \star}$ & $100.181^{\star \star \star}$ & & & & & \\
\hline [15.358] & [12.828] & [12.838] & & & & & \\
\hline$-25.905^{\star \star \star}$ & $-30.018^{* \star *}$ & $-29.581^{\star \star \star}$ & $-25.498^{\star \star \star}$ & $-25.526^{\star \star \star}$ & $-20.387^{* \star *}$ & $-11.985^{\star \star \star}$ & $2.534^{\star \star \star}$ \\
\hline [4.524] & [2.540] & [2.532] & [3.083] & [3.083] & [2.039] & [1.624] & {$[0.826]$} \\
\hline$-26.827^{\star \star \star}$ & $-28.287^{\star \star \star}$ & $-27.892^{\star \star \star}$ & $-28.225^{\star \star \star}$ & $-28.286^{\star \star \star}$ & $-13.132^{\star \star *}$ & $-15.420^{\star \star \star}$ & $-1.287^{\star}$ \\
\hline [3.196] & [1.994] & [1.986] & [2.294] & [2.294] & [1.413] & [1.233] & [0.659] \\
\hline-3.985 & $-6.166^{\star \star \star}$ & $-5.632^{\star \star \star}$ & $-7.875^{\star \star \star}$ & $-7.994^{\star \star \star}$ & $-4.513^{\star \star \star}$ & $-12.549 * \star \star$ & $6.306^{\star * *}$ \\
\hline [3.801] & [2.038] & [2.034] & [2.325] & [2.325] & [1.415] & [1.414] & [0.731] \\
\hline$-6.266^{\star *}$ & $-6.412^{\star \star \star}$ & $-6.346^{\star \star \star}$ & 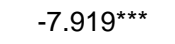 & $-8.042^{\star \star *}$ & 2.209 & $-11.180^{\star \star \star}$ & 0.708 \\
\hline [3.074] & [2.053] & [2.046] & [2.354] & [2.355] & [1.549] & [1.314] & [0.598] \\
\hline-2.239 & -2.425 & -3.145 & -1.105 & -0.539 & $-2.968^{\star}$ & $-7.755^{\star \star \star}$ & $9.028^{\star \star *}$ \\
\hline [3.564] & [2.103] & [2.092] & [2.418] & [2.412] & [1.548] & [1.425] & [0.587] \\
\hline $6.534^{*}$ & $8.078^{* * *}$ & 7.911 *** & $7.637^{* * *}$ & $7.858^{\star \star \star}$ & $-6.935^{\star \star \star}$ & -0.321 & $12.955^{\star \star \star}$ \\
\hline [3.594] & [2.124] & [2.119] & [2.419] & [2.418] & [1.434] & [1.409] & {$[0.604]$} \\
\hline $27.344^{\star \star \star}$ & $27.337^{\star \star \star}$ & 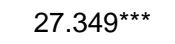 & $24.292^{\star * *}$ & $24.379 * * *$ & $-4.888^{\star \star \star}$ & $9.986^{* * *}$ & $16.456^{\star \star \star}$ \\
\hline [3.796] & [2.112] & [2.110] & [2.430] & [2.429] & [1.501] & [1.392] & [0.612] \\
\hline $42.123^{\star \star \star}$ & $41.957^{\star \star \star}$ & $42.325^{\star \star \star}$ & $39.431^{\star \star \star}$ & $39.393^{\star \star \star}$ & $-3.267^{*}$ & $22.277^{\star \star \star}$ & $19.733^{\star \star \star}$ \\
\hline [3.740] & [2.339] & [2.334] & [2.671] & [2.671] & [1.784] & [1.571] & [0.661] \\
\hline $55.333^{\star \star \star}$ & $48.340 * \star \star$ & $48.722^{\star \star \star}$ & $47.460^{\star \star \star}$ & $47.352^{\star \star \star}$ & $-5.639 * \star \star$ & $30.240 * \star \star$ & $21.491^{\star \star \star}$ \\
\hline [4.127] & [2.246] & [2.242] & [2.560] & [2.561] & [1.544] & [1.555] & {$[0.670]$} \\
\hline
\end{tabular}




\begin{tabular}{|c|c|c|c|c|c|c|c|c|}
\hline females aged 45-49 & $\begin{array}{c}83.608^{\star * *} \\
{[5.256]}\end{array}$ & $\begin{array}{c}\text { 72.951*** } \\
{[2.587]}\end{array}$ & $\begin{array}{c}73.269 * * * \\
{[2.580]}\end{array}$ & $\begin{array}{c}72.187^{\star \star \star} \\
{[2.934]}\end{array}$ & $\begin{array}{c}72.054 * \star \star \\
{[2.934]}\end{array}$ & $\begin{array}{l}-2.246 \\
{[1.791]}\end{array}$ & $\begin{array}{c}43.298^{\star \star \star} \\
{[1.759]}\end{array}$ & $\begin{array}{c}27.910 * \star \star \\
{[0.759]}\end{array}$ \\
\hline females aged $50-54$ & $\begin{array}{c}116.499^{* * *} \\
{[5.475]}\end{array}$ & $\begin{array}{c}99.410^{* * *} \\
{[2.815]}\end{array}$ & $\begin{array}{c}99.756^{* * *} \\
{[2.811]}\end{array}$ & $\begin{array}{c}100.411^{* * *} \\
{[3.258]}\end{array}$ & $\begin{array}{c}100.230^{* * *} \\
{[3.259]}\end{array}$ & $\begin{array}{l}3.494^{*} \\
{[1.983]}\end{array}$ & $\begin{array}{c}58.210^{\star * *} \\
{[2.037]}\end{array}$ & $\begin{array}{c}32.986^{* * *} \\
{[0.807]}\end{array}$ \\
\hline females aged 55-59 & $\begin{array}{c}145.882^{\star \star \star} \\
{[5.613]}\end{array}$ & $\begin{array}{c}138.527^{\star \star \star} \\
{[3.125]}\end{array}$ & $\begin{array}{c}138.764^{\star \star \star} \\
{[3.119]}\end{array}$ & $\begin{array}{c}136.9966^{\star \star \star} \\
{[3.515]}\end{array}$ & $\begin{array}{c}136.774^{\star \star *} \\
{[3.515]}\end{array}$ & $\begin{array}{c}12.848^{\star \star \star} \\
{[1.994]}\end{array}$ & $\begin{array}{c}76.963^{\star \star \star} \\
{[2.254]}\end{array}$ & $\begin{array}{c}39.512^{\star \star *} \\
{[0.869]}\end{array}$ \\
\hline females aged 60-64 & $\begin{array}{c}210.316^{\star \star \star} \\
{[7.340]}\end{array}$ & $\begin{array}{c}204.924^{\star \star \star} \\
{[3.824]}\end{array}$ & $\begin{array}{c}205.115^{\star \star \star} \\
{[3.826]}\end{array}$ & $\begin{array}{c}201.209^{\star * *} \\
{[4.287]}\end{array}$ & $\begin{array}{c}200.934^{* \star *} \\
{[4.289]}\end{array}$ & $\begin{array}{c}35.906^{\star \star \star} \\
{[2.599]}\end{array}$ & $\begin{array}{c}106.441^{* * *} \\
{[2.621]}\end{array}$ & $\begin{array}{c}46.661^{* * *} \\
{[0.927]}\end{array}$ \\
\hline females aged 65-69 & $\begin{array}{c}305.235^{\star \star \star} \\
{[8.924]}\end{array}$ & $\begin{array}{c}313.520^{\star \star *} \\
{[4.843]}\end{array}$ & $\begin{array}{c}313.356^{\star \star \star} \\
{[4.840]}\end{array}$ & $\begin{array}{c}313.155^{\star \star \star} \\
{[5.541]}\end{array}$ & $\begin{array}{c}312.824^{\star \star *} \\
{[5.542]}\end{array}$ & $\begin{array}{c}90.045^{\star \star \star} \\
{[3.592]}\end{array}$ & $\begin{array}{c}143.013^{\star \star *} \\
{[3.319]}\end{array}$ & $\begin{array}{c}59.600^{\star \star \star} \\
{[1.126]}\end{array}$ \\
\hline females aged $70-74$ & $\begin{array}{c}442.255^{\star \star \star} \\
{[11.018]}\end{array}$ & $\begin{array}{c}437.202^{\star \star \star} \\
{[5.461]}\end{array}$ & $\begin{array}{c}436.949^{\star \star \star} \\
{[5.454]}\end{array}$ & $\begin{array}{c}428.955^{\star \star \star} \\
{[6.295]}\end{array}$ & $\begin{array}{c}428.588^{* \star *} \\
{[6.297]}\end{array}$ & $\begin{array}{c}169.465^{\star \star \star} \\
{[4.114]}\end{array}$ & $\begin{array}{c}168.990^{\star \star \star} \\
{[3.871]}\end{array}$ & $\begin{array}{c}65.578^{\star * \star} \\
{[1.073]}\end{array}$ \\
\hline females aged 75-79 & $\begin{array}{c}577.341^{\star \star \star} \\
{[12.413]}\end{array}$ & $\begin{array}{c}602.705^{\star \star \star} \\
{[6.625]}\end{array}$ & $\begin{array}{c}602.174^{\star \star \star} \\
{[6.620]}\end{array}$ & $\begin{array}{c}596.728^{\star \star \star} \\
{[7.800]}\end{array}$ & $\begin{array}{c}596.318^{\star \star \star} \\
{[7.799]}\end{array}$ & $\begin{array}{c}315.451^{\star \star \star} \\
{[5.323]}\end{array}$ & $\begin{array}{c}171.712^{\star \star \star} \\
{[4.575]}\end{array}$ & $\begin{array}{c}70.522^{\star \star \star} \\
{[1.179]}\end{array}$ \\
\hline females aged $80-84$ & $\begin{array}{c}730.523^{\star \star \star} \\
{[13.866]}\end{array}$ & $\begin{array}{c}781.650 \text { *** } \\
{[7.722]}\end{array}$ & $\begin{array}{c}780.755^{\star \star \star} \\
{[7.720]}\end{array}$ & $\begin{array}{c}782.183^{\star \star \star} \\
{[9.122]}\end{array}$ & $\begin{array}{c}781.752^{\star \star *} \\
{[9.126]}\end{array}$ & $\begin{array}{c}541.031^{\star \star \star} \\
{[7.160]}\end{array}$ & $\begin{array}{c}127.826^{\star \star \star} \\
{[4.230]}\end{array}$ & $\begin{array}{c}65.061^{\star * *} \\
{[1.409]}\end{array}$ \\
\hline females aged over 85 & $\begin{array}{c}984.768^{\star \star \star} \\
{[19.499]}\end{array}$ & $\begin{array}{c}1,059.716^{\star \star *} \\
{[9.295]}\end{array}$ & $\begin{array}{c}1,058.386^{\star \star *} \\
{[9.296]}\end{array}$ & $\begin{array}{c}1,064.372^{\star \star *} \\
{[10.811]}\end{array}$ & $\begin{array}{c}1,063.915^{\star \star \star} \\
{[10.812]}\end{array}$ & $\begin{array}{c}882.623^{\star \star \star} \\
{[8.885]}\end{array}$ & $\begin{array}{c}77.182^{\star \star \star} \\
{[4.638]}\end{array}$ & $\begin{array}{c}35.239^{\star \star \star} \\
{[1.095]}\end{array}$ \\
\hline \multicolumn{9}{|l|}{ Past hospital encounters } \\
\hline number of episodes & $\begin{array}{c}298.628^{\star \star \star} \\
{[9.938]}\end{array}$ & $\begin{array}{c}288.928^{\star \star \star} \\
{[4.285]}\end{array}$ & $\begin{array}{c}289.002^{* * *} \\
{[4.283]}\end{array}$ & $\begin{array}{c}242.669^{\star \star \star} \\
{[4.081]}\end{array}$ & $\begin{array}{c}242.669 \star \star \star \star \\
{[4.081]}\end{array}$ & $\begin{array}{c}11.823^{\star \star *} \\
{[0.828]}\end{array}$ & $\begin{array}{c}201.800^{\star \star *} \\
{[4.328]}\end{array}$ & $\begin{array}{c}1.842^{\star * *} \\
{[0.368]}\end{array}$ \\
\hline number attendances & $\begin{array}{c}45.712^{\star \star \star} \\
{[2.211]}\end{array}$ & $\begin{array}{c}49.476^{\star \star \star} \\
{[0.593]}\end{array}$ & $\begin{array}{c}49.577^{\star \star *} \\
{[0.592]}\end{array}$ & $\begin{array}{c}41.021^{\star \star \star} \\
{[0.661]}\end{array}$ & $\begin{array}{c}41.011^{\star * \star} \\
{[0.661]}\end{array}$ & $\begin{array}{c}8.507^{\star \star *} \\
{[0.269]}\end{array}$ & $\begin{array}{c}9.144^{\star \star \star} \\
{[0.344]}\end{array}$ & $\begin{array}{c}0.719 \\
{[1.254]}\end{array}$ \\
\hline Outpatient priority referral & $\begin{array}{l}70.965^{\star \star \star} \\
{[10.590]}\end{array}$ & $\begin{array}{c}107.030^{\star \star \star} \\
{[3.463]}\end{array}$ & $\begin{array}{c}106.849^{\star \star *} \\
{[3.461]}\end{array}$ & $\begin{array}{c}85.185^{\star * \star} \\
{[3.659]}\end{array}$ & $\begin{array}{c}85.106^{\star * *} \\
{[3.659]}\end{array}$ & $\begin{array}{c}16.132^{\star \star \star} \\
{[2.160]}\end{array}$ & $\begin{array}{c}55.142^{\star \star \star} \\
{[2.155]}\end{array}$ & $\begin{array}{c}-13.782^{\star \star *} \\
{[1.907]}\end{array}$ \\
\hline Outpatient treatment & $\begin{array}{c}55.845^{\star \star \star} \\
{[12.415]}\end{array}$ & $\begin{array}{c}37.174^{\star \star \star} \\
{[4.790]}\end{array}$ & $\begin{array}{c}36.742^{\star \star *} \\
{[4.766]}\end{array}$ & $\begin{array}{c}27.134^{\star \star \star} \\
{[5.050]}\end{array}$ & $\begin{array}{c}27.113^{\star \star \star} \\
{[5.050]}\end{array}$ & $\begin{array}{c}-19.191^{\star \star *} \\
{[3.047]}\end{array}$ & $\begin{array}{c}40.612^{\star \star *} \\
{[3.234]}\end{array}$ & $\begin{array}{c}-8.695^{\star \star \star} \\
{[1.488]}\end{array}$ \\
\hline Past private hospital & & & & & & & & \\
\hline private attendance & $\begin{array}{c}-168.255^{\star * *} \\
{[25.153]}\end{array}$ & $\begin{array}{c}-137.481^{* * *} \\
{[13.234]}\end{array}$ & $\begin{array}{c}-138.798^{\star * *} \\
{[13.240]}\end{array}$ & $\begin{array}{c}-122.626^{* * *} \\
{[13.795]}\end{array}$ & $\begin{array}{c}-122.523^{\star \star \star} \\
{[13.797]}\end{array}$ & $\begin{array}{c}-36.251^{\star \star \star} \\
{[8.641]}\end{array}$ & $\begin{array}{c}-47.655^{\star \star \star} \\
{[8.464]}\end{array}$ & $\begin{array}{c}14.103^{\star \star \star} \\
{[3.438]}\end{array}$ \\
\hline private episodes & $\begin{array}{c}-491.478^{\star \star *} \\
{[24.625]}\end{array}$ & $\begin{array}{c}-468.248^{\star * *} \\
{[15.506]}\end{array}$ & $\begin{array}{c}-470.636^{\star * *} \\
{[15.525]}\end{array}$ & $\begin{array}{c}-345.384^{* \star *} \\
{[18.348]}\end{array}$ & $\begin{array}{c}-345.360^{\star \star *} \\
{[18.348]}\end{array}$ & $\begin{array}{c}165.139^{\star \star *} \\
{[11.119]}\end{array}$ & $\begin{array}{c}114.463^{* * *} \\
{[12.090]}\end{array}$ & $\begin{array}{c}-15.185^{\star \star \star} \\
{[2.378]}\end{array}$ \\
\hline
\end{tabular}




\begin{tabular}{|c|c|c|c|c|c|c|c|c|}
\hline \multicolumn{9}{|l|}{ Year dummies } \\
\hline year 2 dummy & & {$[1.446]$} & {$[1.361]$} & {$[1.571]$} & {$[1.571]$} & [0.997] & {$[0.876]$} & {$[0.396]$} \\
\hline \multirow[t]{2}{*}{ year 3 dummy } & & $-21.033^{\star \star \star}$ & $-20.064^{\star \star \star}$ & $32.412^{\star \star *}$ & $32.408^{\star \star *}$ & $28.676^{* \star *}$ & $4.545^{\star \star *}$ & $-3.743^{\star \star *}$ \\
\hline & & {$[2.105]$} & {$[1.796]$} & {$[1.621]$} & [1.621] & {$[1.055]$} & {$[0.877]$} & [0.329] \\
\hline \multirow[t]{2}{*}{ year 4 dummy } & & $-55.337^{\star \star \star}$ & $-54.373^{\star \star \star}$ & & & & & \\
\hline & & {$[1.970]$} & {$[1.611]$} & & & & & \\
\hline \multicolumn{9}{|l|}{ Attributed needs variables } \\
\hline \multirow[t]{2}{*}{ in social rented housing } & $0.342^{\star * *}$ & $0.306^{\star \star *}$ & $0.347^{\star * *}$ & $0.386^{* * *}$ & $0.407^{\star \star *}$ & $0.356^{\star \star \star}$ & -0.005 & $0.042^{* * *}$ \\
\hline & {$[0.101]$} & {$[0.056]$} & {$[0.049]$} & {$[0.056]$} & {$[0.056]$} & {$[0.037]$} & {$[0.032]$} & {$[0.010]$} \\
\hline \multirow[t]{2}{*}{ disability living allowance } & $292.772^{\star \star \star}$ & $433.599 * \star \star$ & $413.832^{\star \star \star}$ & $432.916^{\star \star \star}$ & $410.730^{\star \star \star}$ & $331.005^{\star \star \star}$ & 39.095 & $37.276^{\star \star \star}$ \\
\hline & {$[79.592]$} & [48.667] & {$[43.526]$} & {$[50.657]$} & {$[50.870]$} & [33.458] & [28.855] & {$[8.488]$} \\
\hline \multirow[t]{2}{*}{ no qualifications standardised } & $23.136^{\star \star *}$ & $19.466^{\star \star *}$ & $20.080^{* * *}$ & $18.025^{\star \star *}$ & $17.209^{\star * *}$ & $7.307^{\star \star \star}$ & $5.037^{\star \star *}$ & $1.865^{\star * *}$ \\
\hline & {$[4.836]$} & [3.383] & {$[2.779]$} & [3.198] & [3.200] & {$[2.087]$} & {$[1.927]$} & {$[0.487]$} \\
\hline \multirow[t]{2}{*}{ ONS 15: City professionals } & $-22.845^{\star \star \star}$ & 2.345 & -4.329 & -1.020 & -0.410 & 4.507 & 2.253 & $-3.615^{\star *}$ \\
\hline & {$[7.027]$} & {$[5.477]$} & [4.980] & [5.838] & {$[5.826]$} & [3.694] & [3.497] & {$[1.509]$} \\
\hline \multirow[t]{2}{*}{ students in population } & $-1,254.64^{\star \star \star}$ & $-1,302.84^{\star \star \star}$ & $-1,315.06^{\star \star \star}$ & $-1,329.76^{\star \star \star}$ & $-1,324.40^{\star \star *}$ & $-622.02^{\star * *}$ & $-470.47^{\star \star \star}$ & $-185.95^{\star * \star}$ \\
\hline & [138.77] & {$[95.26]$} & [84.15] & [97.29] & [97.31] & {$[62.90]$} & {$[55.31]$} & {$[16.88]$} \\
\hline \multicolumn{9}{|l|}{ Disease management } \\
\hline \multirow[t]{2}{*}{ stroke QOF score } & $-0.664^{\star \star \star}$ & -0.090 & $-0.193^{\star \star}$ & $-0.266^{\star \star}$ & $-0.255^{\star \star}$ & $-0.245^{\star \star \star}$ & 0.072 & $-0.058^{* *}$ \\
\hline & {$[0.190]$} & {$[0.135]$} & {$[0.085]$} & {$[0.117]$} & {$[0.117]$} & {$[0.078]$} & {$[0.065]$} & {$[0.026]$} \\
\hline \multicolumn{9}{|l|}{ Lagged cost variables } \\
\hline \multirow[t]{2}{*}{ lagged one period individual cost } & & & & $0.125^{\star \star \star}$ & $0.125^{\star \star \star}$ & $0.053^{\star \star \star}$ & $0.205^{\star \star \star}$ & $0.558^{\star \star *}$ \\
\hline & & & & {$[0.005]$} & {$[0.005]$} & {$[0.002]$} & {$[0.011]$} & {$[0.030]$} \\
\hline \multirow[t]{2}{*}{ base period individual cost } & & & & $0.016^{\star * *}$ & $0.016^{\star \star *}$ & $0.046^{\star \star *}$ & 0.013 & $0.088^{* * *}$ \\
\hline & & & & {$[0.005]$} & {$[0.005]$} & {$[0.003]$} & {$[0.011]$} & {$[0.015]$} \\
\hline \multirow[t]{2}{*}{ base period practice cost } & & & & & $0.032^{\star \star \star}$ & $0.024^{\star \star \star}$ & $0.023^{\star \star}$ & $0.105^{\star \star \star}$ \\
\hline & & & & & {$[0.007]$} & {$[0.008]$} & {$[0.009]$} & {$[0.007]$} \\
\hline \multirow[t]{2}{*}{ Constant } & $130.476^{\star \star \star}$ & $72.433^{\star \star \star}$ & $112.274^{\star \star \star}$ & $88.511^{\star \star *}$ & $76.304^{\star \star *}$ & $23.638^{\star \star}$ & $28.715^{\star \star \star}$ & $23.741^{\star \star \star}$ \\
\hline & [17.584] & {$[10.881]$} & [10.039] & [13.788] & [13.882] & {$[9.981]$} & {$[8.037]$} & {$[2.637]$} \\
\hline
\end{tabular}


Robust standard errors in

brackets

*** $p<0.01,{ }^{* *} p<0.05,{ }^{*} p<0.1$

Note: The dependent variable in all models is individual hospital cost in a year. Model 1 is a one period cross-section OLS model with robust standard errors. Model 2 is a fixed (practice) effects model with robust standard errors clustered by general practice. Model 3 is a random (practice) effects model with robust standard errors clustered by practice. Model 4 is the same as model 3 with the addition of lagged individual cost and base period individual cost. Model 5 is the same as model 4 with the addition of baseline practice cost. Models 6 - 8 are the same as model 5 but employ a different measure of cost as the dependent variable and as regressors. All models also contain 152 ICD10 morbidity dummies and 151 PCT dummies. See Sections 2 and 3 for details. $* * * p<0.01, * * p<0.05$, $*$ p $<0.1$. Full results are in the Working Paper (Dusheiko et al, 2011) 